ARTICLE

\title{
A contorted nanographene shelter
}

\author{
Huang Wu (1) 1, Yu Wang (10 1, Bo Song (1) 1, Hui-Juan Wang', Jiawang Zhou ${ }^{3}$, Yixun Sun ${ }^{4}$, Leighton O. Jones (1) ${ }^{1}$, \\ Wenqi Liu', Long Zhang (10 ${ }^{1}$, Xuan Zhang ${ }^{1}$, Kang Cai ${ }^{2}$, Xiao-Yang Chen (1) ${ }^{1}$, Charlotte L. Stern (1) ${ }^{1}$, Junfa Wei ${ }^{4}$,

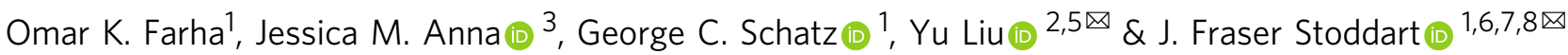

\begin{abstract}
Nanographenes have kindled considerable interest in the fields of materials science and supramolecular chemistry as a result of their unique self-assembling and optoelectronic properties. Encapsulating the contorted nanographenes inside artificial receptors, however, remains challenging. Herein, we report the design and synthesis of a trigonal prismatic hexacationic cage, which has a large cavity and adopts a relatively flexible conformation. It serves as a receptor, not only for planar coronene, but also for contorted nanographene derivatives with diameters of approximately $15 \AA$ and thicknesses of $7 \AA$. A comprehensive investigation of the host-guest interactions in the solid, solution and gaseous states by experimentation and theoretical calculations reveals collectively an induced-fit binding mechanism with high binding affinities between the cage and the nanographenes. Notably, the photostability of the nanographenes is improved significantly by the ultrafast deactivation of their excited states within the cage. Encapsulating the contorted nanographenes inside the cage provides a noncovalent strategy for regulating their photoreactivity.
\end{abstract}

\footnotetext{
${ }^{1}$ Department of Chemistry, Northwestern University, Evanston, IL, USA. ${ }^{2}$ College of Chemistry, State Key Laboratory of Elemento-Organic Chemistry, Nankai University, Nankai District, Tianjin, China. ${ }^{3}$ Department of Chemistry, University of Pennsylvania, Philadelphia, PA, USA. ${ }^{4}$ Key Laboratory of Applied Surface and Colloid Chemistry (Ministry of Education), Key Laboratory for Macromolecular Science of Shaanxi Province, School of Chemistry and Chemical Engineering, Shaanxi Normal University, Xi'an, China. ${ }^{5}$ Collaborative Innovation Center of Chemical Science and Engineering (Tianjin), Nankai District, Tianjin, China. ${ }^{6}$ School of Chemistry, University of New South Wales, Sydney, NSW, Australia. ${ }^{7}$ Stoddart Institute of Molecular Science, Department of Chemistry, Zhejiang University, Hangzhou, China. ${ }^{8}$ ZJU-Hangzhou Global Scientific and Technological Innovation Center, Hangzhou, China.

凶email: yuliu@nankai.edu.cn; stoddart@northwestern.edu
} 
$\mathrm{N}$ anographenes $^{1-4}$ (NGs), a class of large polycyclic aromatic hydrocarbons (PAHs) that extend over $1.0 \mathrm{~nm}^{5}$, have attracted considerable attention both in the scientific community and in technological spheres on account of their unique selfassembling $^{6,7}$, redox $^{8}$, and optoelectronic properties ${ }^{9-11}$. Of particular interest are the coronene (COR) homologous molecules (Fig. 1a), such as the bowl-like corannulene ${ }^{12}$, planar hexa-perihexabenzocoronene $e^{13-15}(\boldsymbol{p}$-HBC) and contorted hexa-catahexabenzocoronene ${ }^{16,17}$ (c-HBC), which have been widely applied in field-effect transistors ${ }^{18}$, light-emitting diodes ${ }^{19}$, and nonlinear optical materials ${ }^{20}$. Along with the advent of supramolecular chemistry $^{21-26}$, investigations ${ }^{27-29}$ on artificial receptors for PAHs, on the basis of noncovalent bonding interactions, have become an active research area in recent decades. To date, a series of receptors, including, macrocycles ${ }^{30}$, tweezers ${ }^{31}$, covalent $^{32}$, and coordination $^{33,34}$ cages, as well as carbon nanotubes ${ }^{35}$, have been synthesized as hosts for COR. Several receptors ${ }^{36-40}$ are even able to bind bowl-like corannulene, despite the fact that they show lower binding affinities compared to that for COR. Well-crafted receptors for the larger and contorted $\boldsymbol{c}$-HBC, however, are still few and far between, for the simple reason that their contorted conformations lead to (i) weaker $[\pi \cdots \pi]$ interactions between the hosts and guests, and (ii) less shape complementarity in order to fit within the cavity of the host ${ }^{36,40}$. In addition, large nanographenes often suffer from instability upon exposure to light ${ }^{41,42}$, reducing considerably the stability and life of graphene-based materials. Typical examples are the acenes ${ }^{43,44}$ larger than pentacene, an important class of onedimensional nanographenes, which have been found to be unstable to light. This deficiency limits their utility severely. Hence, designing an artificial receptor, with the property of high binding affinities toward nanographenes and protecting them from photo-degradation, is a challenging, yet worthwhile, objective in noncovalent synthesis.

Macrocyclic arenes, such as calix[n]arenes ${ }^{45}$, calixpyrroles ${ }^{46,47}$, cyanostars $^{48,49}$, and pillar[n]arenes ${ }^{50,51}$, represent a rapidly growing family of molecular receptors that play a crucial role in supramolecular chemistry by virtue of their properties of molecular recognition towards various guests. As a representative cationic cyclophane, cyclobis(paraquat- $p$-phenylene) $)^{52,53}$ (CBPQT $^{4+}$, Fig. 1b), not only shows excellent molecular recognition properties ${ }^{54}$ but also serves as a vital building block for constructing mechanically interlocked molecules $^{55}$ (MIMs). In attempts to modulate the dimensions of CBPQT $^{4+}$, the 1,4-disubstituted phenylene rings have been replaced by 1,3,5-trisubstituted benzenoid ones in order to obtain cage-like cyclophanes $^{56}$, such as, ExCage ${ }^{6+}$ (Fig. 1b), which exhibits higher complexation strengths towards a series of neutral PAHs. Upon changing the central benzenoid rings within ExCage $^{6+}$ into $\pi-$ electron-deficient triazine rings, a more electron-poor cyclophane ${ }^{57}$, so-called BlueCage ${ }^{6+}$ (Fig. 1b), was obtained. Since it acts as a receptor for both planar aromatic guests and $\left[\mathrm{PF}_{6}\right]^{-}$anions, binding affinities for the aromatic guests can be controlled by anion- $\pi$ interactions. These two cage-like receptors, however, can only bind planar and relatively small aromatic guests because of their rigid conformations and the limited space within their cavities.

In this investigation, we introduced two triphenylamine units into a hexacationic cage, TPACage ${ }^{6+}$ (Fig. 1c). Its solid-state structure reveals that the cage adopts a relatively flexible conformation and has a large cavity with a diameter of $20.8 \AA$ and a volume of $368 \AA^{3}$. As a result, TPACage ${ }^{6+}$ can form 1:1 complexes, not only with planar COR but also with large contorted $c$ HBC derivatives with diameters of $15.3 \AA$, as evidenced by singlecrystal X-ray diffraction, NMR spectroscopy, and high-resolution mass spectrometry (HRMS). Benefiting from ideal size-matching, TPACage $^{6+}$ shows higher binding affinities towards $\boldsymbol{c}$-HBC derivatives than that with COR in the solution state. Gradient tandem mass spectrometry revealed that as the electron density of guests increases, the stability of the host-guest complexes are enhanced in the gas phase. As a consequence of the ultrafast energy transfer between the host and guests, the photostability of $\boldsymbol{c}$-HBC guests is significantly improved within the cavity of TPACage $^{6+}$, as confirmed by femtosecond transient absorption spectroscopy.

\section{Results}

Synthesis and characterization of TPACage ${ }^{6+}$. The TPACage ${ }^{6+}$ was synthesized (Fig. 1c and Supplementary Figs. 1-3) in three steps from commercially available starting materials. A coupling reaction between tris(4-bromophenyl)amine and 4-vinylpyridine in triethylamine was carried out under reflux for $6 \mathrm{~h}$ to obtain TPAP in a $58 \%$ yield. Thereafter, an $\mathrm{S}_{\mathrm{N}} 2$ reaction between an excess of $p$-xylylene dibromide and TPAP in a MeCN/DMF a
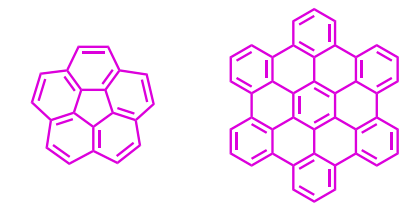

Corannulene

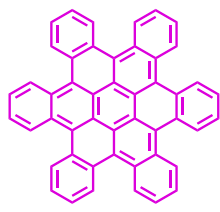

p-HBC b

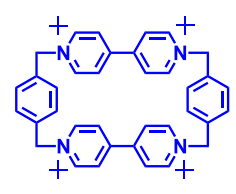

$\mathrm{CBPQT}^{4+}$
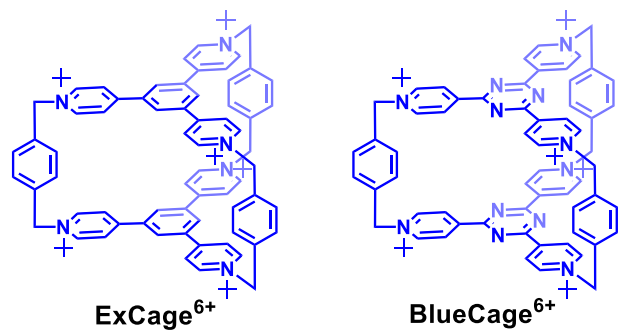

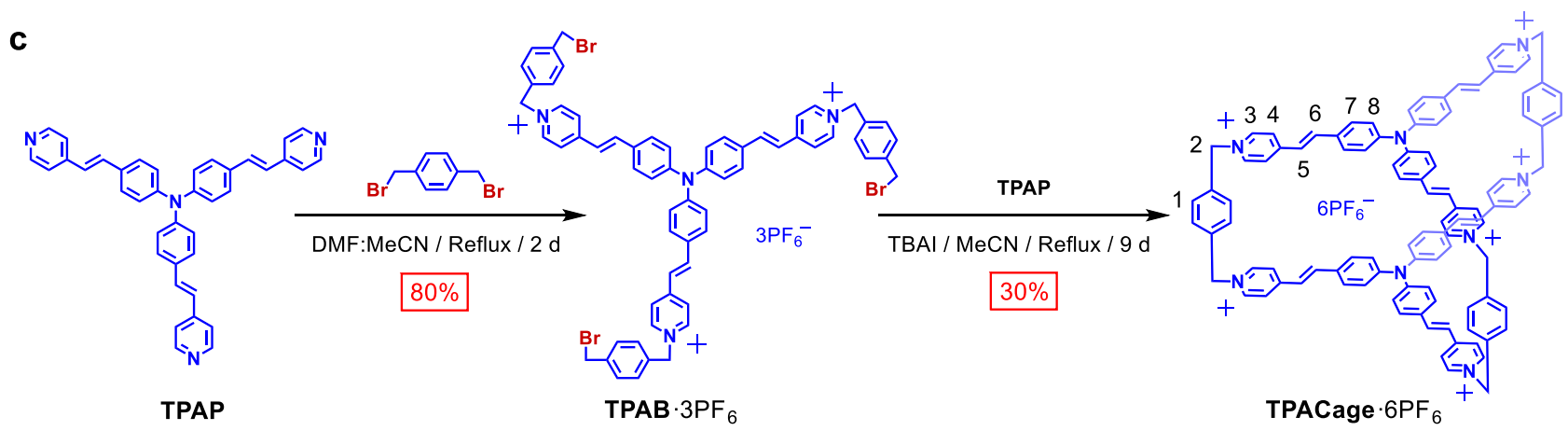

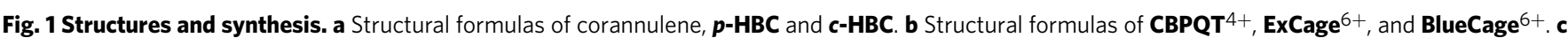
Synthesis and labeling of protons on TPACage ${ }^{6+}$. 

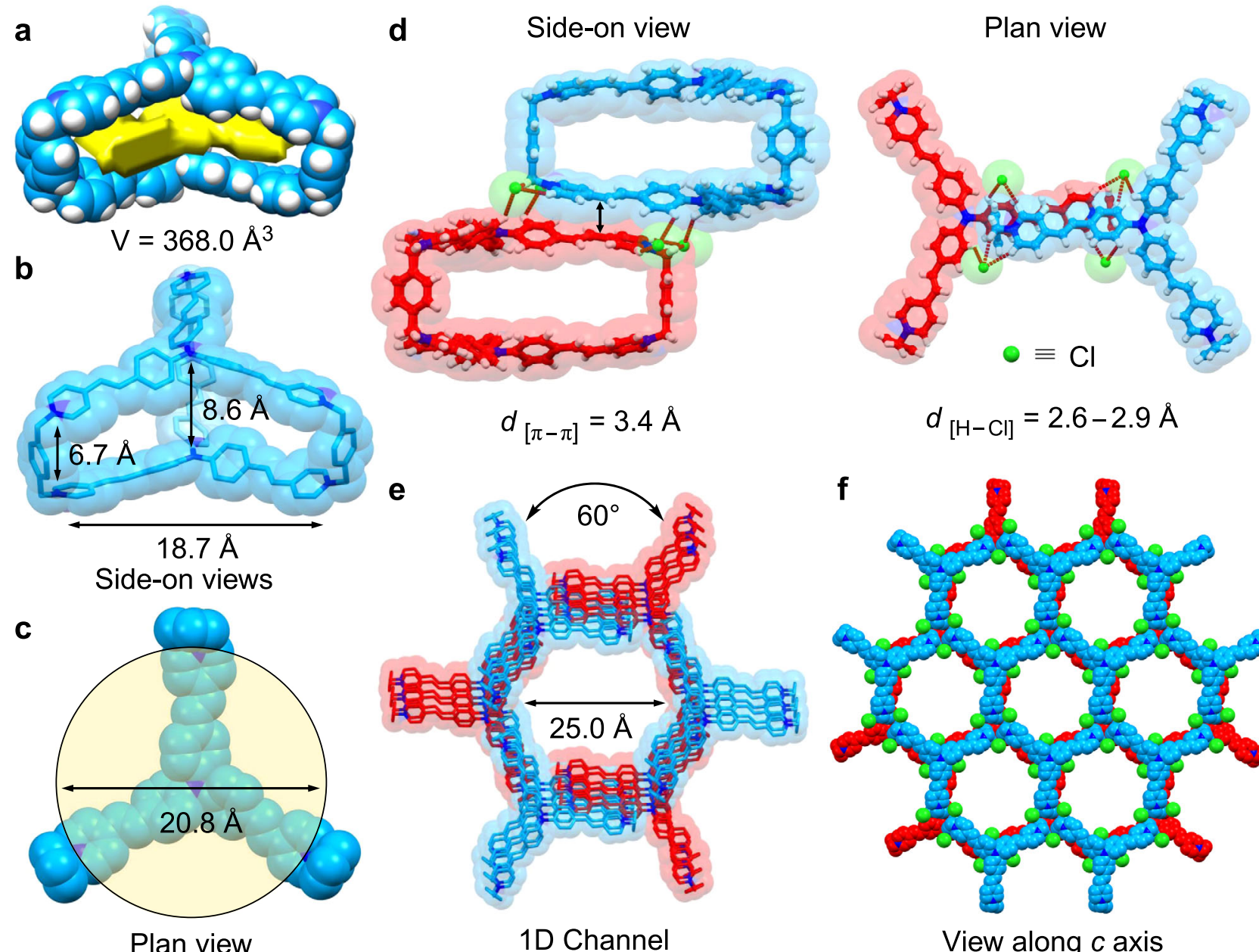

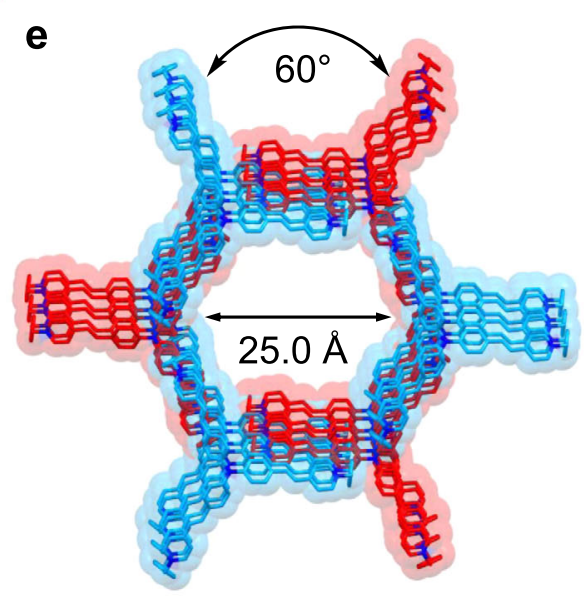

1D Channel

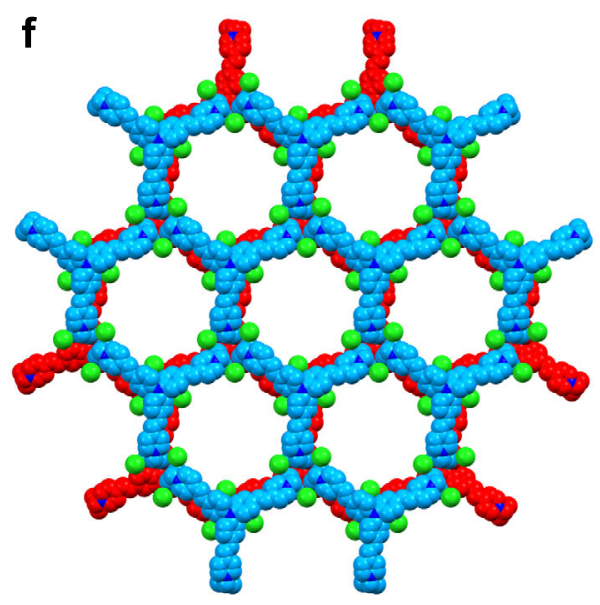

View along $c$ axis

Fig. 2 Solid-state (super)structure of TPACage•6Cl. a-b Capped-stick and space-filling representations of side-on views, showing the volume and

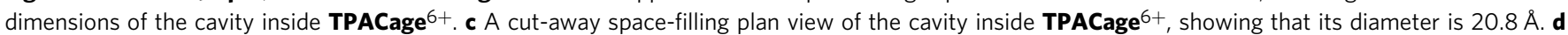
Capped-stick and space-filling representations of different views, showing the $[\pi \cdots \pi]$ stacking interaction between two adjacent cages and the $[\mathrm{C}-\mathrm{H} \cdots \mathrm{Cl}-]$ hydrogen bonding between TPACage ${ }^{6+}$ and $\mathrm{Cl}^{-}$anions. e-f The solid-state superstructure of TPACage•6Cl, revealing how TPACage ${ }^{6+}$ assembles into a $3 \mathrm{D}$ framework with relatively large $1 \mathrm{D}$ channels with diameter of $25.0 \AA$. Solvent molecules have been omitted for the sake of clarity. $\mathrm{C}$ skyblue and red, $\mathrm{H}$ white, $\mathrm{N}$ blue, $\mathrm{Cl}$ green.

mixture under reflux for 2 days led to the formation of TPAB. $3 \mathrm{PF}_{6}$ after counterion exchange in a yield of $80 \%$. Finally, equimolar amounts of TPAB. $3 \mathbf{P F}_{6}$ and TPAP in the presence of 0.2 equiv. of tetrabutylammonium iodide (TBAI) as a catalyst were heated under reflux in $\mathrm{MeCN}$ for 9 days, resulting in the isolation of the crude chloride salt as a red solid after precipitating with tetrabutylammonium chloride (TBACl). The desired product TPACage $6 \mathrm{PF}_{6}$ was obtained in $30 \%$ yield after purification by reverse-phase column chromatography, followed by counterion exchange $\left(\mathrm{NH}_{4} \mathrm{PF}_{6} / \mathrm{H}_{2} \mathrm{O}\right)$. Furthermore, another two saltsnamely TPACage $6 \mathrm{Cl}$ and TPACage $\cdot 6 \mathrm{AsF}_{6}$-were obtained from TPACage $6 \mathrm{PF}_{6}$ by counterion exchange in yields of $95 \%$ and $96 \%$, respectively.

TPACage $^{6+}$ was fully characterized by one-dimensional (1D, Supplementary Figs. 9-15) and two-dimensional (2D, Supplementary Figs. 22-26) ${ }^{1} \mathrm{H} /{ }^{13} \mathrm{C}$ NMR spectroscopies, as well as by high-resolution mass spectrometry (HRMS). In the HRMS of TPACage $6 \mathrm{PF}_{6}$, peaks with $\mathrm{m} / z$ values of 313.1297 ([TPACage $\left.\left.\cdot \mathrm{PF}_{6}\right]^{5+}\right), \quad 427.6539$ ([TPACage $\left.\left.2 \mathrm{PF}_{6}\right]^{4+}\right)$, and 618.5258 $\left(\left[\text { TPACage } 3 \mathrm{PF}_{6}\right]^{3+}\right.$ ) were observed (Supplementary Fig. 36), and were shown to be consistent with the calculated values. The UV-Vis absorption spectrum of TPACage $6 \mathrm{PF}_{6}$ shows (Supplementary Fig. 46) a strong absorption at $487 \mathrm{~nm}$, which originates from the 4-vinylpyridine-modified triphenylamine units in TPACage $^{6+}$.

The solid-state (super)structure of TPACage ${ }^{6+}$ was determined unambiguously by single-crystal X-ray diffraction analysis of a dark red crystal, which was obtained by slow vapor diffusion of $i \mathrm{Pr}_{2} \mathrm{O}$ into a $\mathrm{MeOH}$ solution of TPACage $6 \mathrm{Cl}$ after four days. The cage displays (Fig. 2a) $D_{3 \mathrm{~h}}$ symmetry, and possesses (Fig. 2b) three identical large rectangular windows with average dimensions of $18.7 \times 6.7 \AA^{2}$. These rectangular windows allow potential guests to undergo association/dissociation with the internal cavity of the cage. The distance between the two central nitrogen atoms in the two TPAP propellers is (Fig. 2b) $8.6 \AA$, which is larger than that $(6.7 \AA)$ between the two nitrogen atoms bridged by the $p$ xylylene linkers. The volume of the resulting slot-like cavity is estimated (Fig. 2 a) to be $368 \AA^{3}$, indicating that TPACage ${ }^{6+}$ may serve as a receptor for some large PAHs. The solid-state superstructure of TPACage ${ }^{6+}$ reveals that it crystallizes in a hexagonal space group $P 6_{3} / \mathrm{m}$ and forms (Fig. 2f) a porous network with interconnected 1D channels. The diameters (Fig. 2e) of these hexagonal channels are $25 \AA$. Each channel is comprised of two styrene-pyridinium arms from three TPACage ${ }^{6+}$ molecules that are positioned in a $C_{3}$-symmetric manner. Every styrene-pyridinium arm within the cage establishes (Fig. 2d) four 
Structural formulas

a<smiles>c1cc2ccc3ccc4ccc5ccc6ccc1c1c2c3c4c5c61</smiles>

Planar COR

d

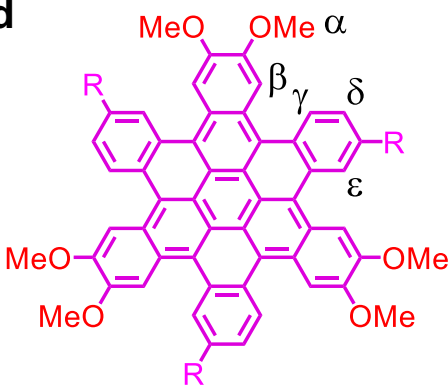

Contorted $\boldsymbol{c}$-HBC $\mathrm{R}=\mathrm{H} / \mathrm{Me} / \mathrm{F}$
Plan views

b

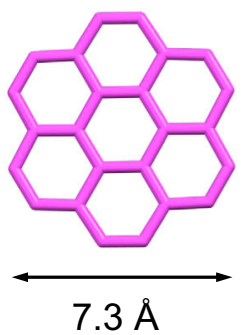

e

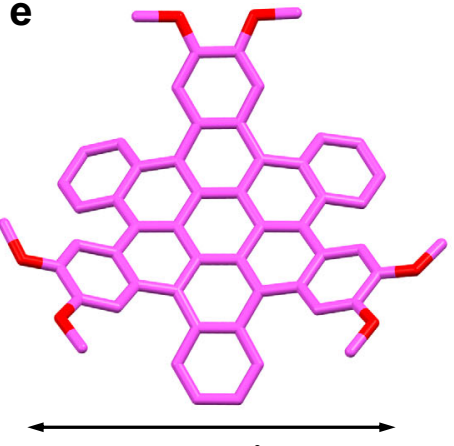

$15.3 \AA$
Side-on views

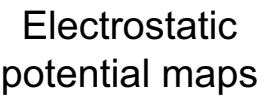

C

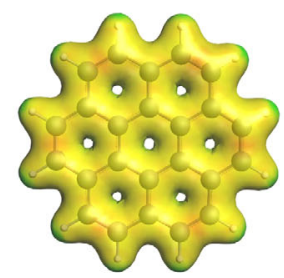

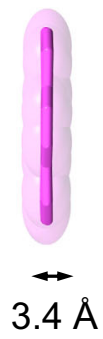

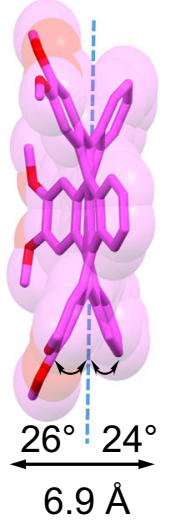

f

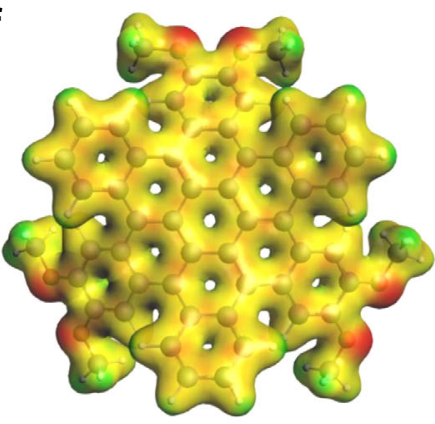

$0.60 \mathrm{Ha}$

Fig. 3 Structure formulas and solid-state structures of guest molecules. a Structural formula and labeling of the proton on the planar COR. $\mathbf{b}$, $\mathbf{c}$ Cappedstick and space-filling representations of the solid-state structure (obtained from CCDC:1129883) and the electrostatic potential map of COR. $\mathbf{d}$ Structural

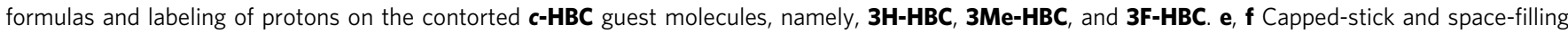
representations of the solid-state structure and electrostatic potential map of $\mathbf{3 H - H B C}$, showing its characteristic dimensions, tilt angles, and electron density distribution.

sets of short contacts with its neighbors through $[\mathrm{C}-\mathrm{H} \cdots \mathrm{Cl}]$ hydrogen bonding interactions with distances in the range of $2.6-2.9 \AA$. Combined with the intermolecular $[\pi \cdots \pi]$ stacking (Fig. 2d) between adjacent styrene-pyridinium arms with a planeto-plane distance of $3.4 \AA$, two sets of three TPACage ${ }^{6+}$ are stacked with each other in a coaxial manner with a perpendicular rotation angle of $60^{\circ}$, forming (Fig. 2e) an infinite hexagonal channel. The third styrene-pyridinium arm within each cage is involved directly in the formation of adjacent channels. Consequently, a three-dimensional (3D) supramolecular organic framework with interconnected $1 \mathrm{D}$ channels along the $c$-axis is formed. This observation indicates that the TPACage ${ }^{6+}$ has the potential for constructing organic porous materials ${ }^{58-60}$.

Solution-phase characterizations of the host-guest complexes. Since the constitution of TPACage ${ }^{6+}$ is based on the well-known family ${ }^{61}$ of "extended viologen cyclophanes", we can anticipate that TPACage ${ }^{6+}$ will be able to encapsulate PAHs as a result of primarily intermolecular $[\pi \cdots \pi]$ interactions. The planar COR (Figs. 3a-c), with a diameter of $7.3 \AA$ and a thickness of $3.4 \AA$, was selected as a representative guest. In the ${ }^{1} \mathrm{H}$ NMR spectrum of an equimolar mixture of TPACage ${ }^{6+}$ and COR, the chemical shifts of both the protons on COR $(\Delta \delta=-0.25$ ppm for $\mathrm{H}-\alpha)$ and on TPACage $^{6+}(\Delta \delta=-0.05,-0.14,-0.12,-0.17$, and $-0.17 \mathrm{ppm}$ for $\mathrm{H}-4, \mathrm{H}-5, \mathrm{H}-6, \mathrm{H}-7$, and $\mathrm{H}-8$, respectively) show (Fig. 4b) significant upfield shifts compared with the chemical shifts of the free COR and the free TPACage ${ }^{6+}$, indicating the presence of aromatic $[\pi \cdots \pi]$ stacking interactions between COR and the styrene-pyridinium units. A $2 \mathrm{D}{ }^{1} \mathrm{H}-{ }^{1} \mathrm{H}$ ROESY spectrum confirmed (Supplementary Fig. 30) the binding mode with throughspace correlations between $\mathrm{H}-\alpha$ on COR and $\mathrm{H}-7$ and $\mathrm{H}-8$ on
TPACage $^{6+}$. A Job plot showed (Supplementary Fig. 29) a maximum at a mole fraction of 0.5 , confirming the existence of a 1:1 stoichiometry between TPACage ${ }^{6+}$ and COR in solution. Upon adding dropwise 8 equiv. of TPACage ${ }^{6+}$ to a $\mathrm{CD}_{3} \mathrm{CN} /$ $\mathrm{CDCl}_{3}(4: 1)$ solution of $\mathbf{C O R}$, the resonance for $\mathrm{H}-\alpha$ on COR moved gradually upfield in the ${ }^{1} \mathrm{H}$ NMR spectra (Supplementary Fig. 27), indicating that the association and disassociation of CORCTPACage ${ }^{6+}$ are undergoing fast exchange on the ${ }^{1} \mathrm{H}$ NMR timescale. The binding constant $\left(K_{\mathrm{a}}\right)$ was determined (Supplementary Fig. 28) to be $1.3 \times 10^{3} \mathrm{M}^{-1}$, according to the chemical shift changes undergone by $\mathrm{H}-\alpha$.

In order to explore the binding ability of TPACage ${ }^{6+}$ towards some larger and thicker PAHs, three $C_{3}$-symmetrical contorted hexa-cata-hexabenzocoronene derivatives (Fig. 3d)-namely, 3HHBC, 3Me-HBC, and 3F-HBC-were synthesized (Supplementary Fig. 4) according to previously reported ${ }^{62}$ protocols. The single-crystal structure of $3 \mathbf{H}-\mathbf{H B C}$ reveals (Fig. 3e) that its diameter reaches $15.3 \AA$, and that it adopts a contorted conformation with a thickness of $6.9 \AA$. Upon adding an equimolar amount of TPACage ${ }^{6+}$ into a $\mathrm{CD}_{3} \mathrm{CN} / \mathrm{CDCl}_{3}(4: 1)$ solution of $3 \mathrm{H}-\mathrm{HBC}$, the chemical shifts for protons on TPACage $^{6+}$ and $\mathbf{3 H}-\mathbf{H B C}$ all show (Fig. 4d) marked changes with some of the peaks undergoing severe broadening in the ${ }^{1} \mathrm{H}$ NMR spectrum, suggesting the formation of a host-guest complex. The peaks in the spectrum were assigned in so far as possible on the basis of in-depth analyses of their $2 \mathrm{D}{ }^{1} \mathrm{H}-{ }^{1} \mathrm{H}$ COSY (Supplementary Fig. 31) and ROESY (Supplementary Fig. 32) spectra. The chemical shifts of protons on the 1,2 -dimethoxybenzene rings $(\Delta \delta=-0.72$ and $-0.29 \mathrm{ppm}$ for $\mathrm{H}-\alpha$ and $\mathrm{H}-\beta$, respectively) in $3 \mathrm{H}-\mathrm{HBC}$ exhibited (Fig. 4d) larger upfield shifts than those of $\mathrm{H}-\gamma$ and $\mathrm{H}-\delta(\Delta \delta=-0.27$ and -0.18 ppm for $\mathrm{H}-\gamma$ and $\mathrm{H}-\delta$, respectively). This observation may result 


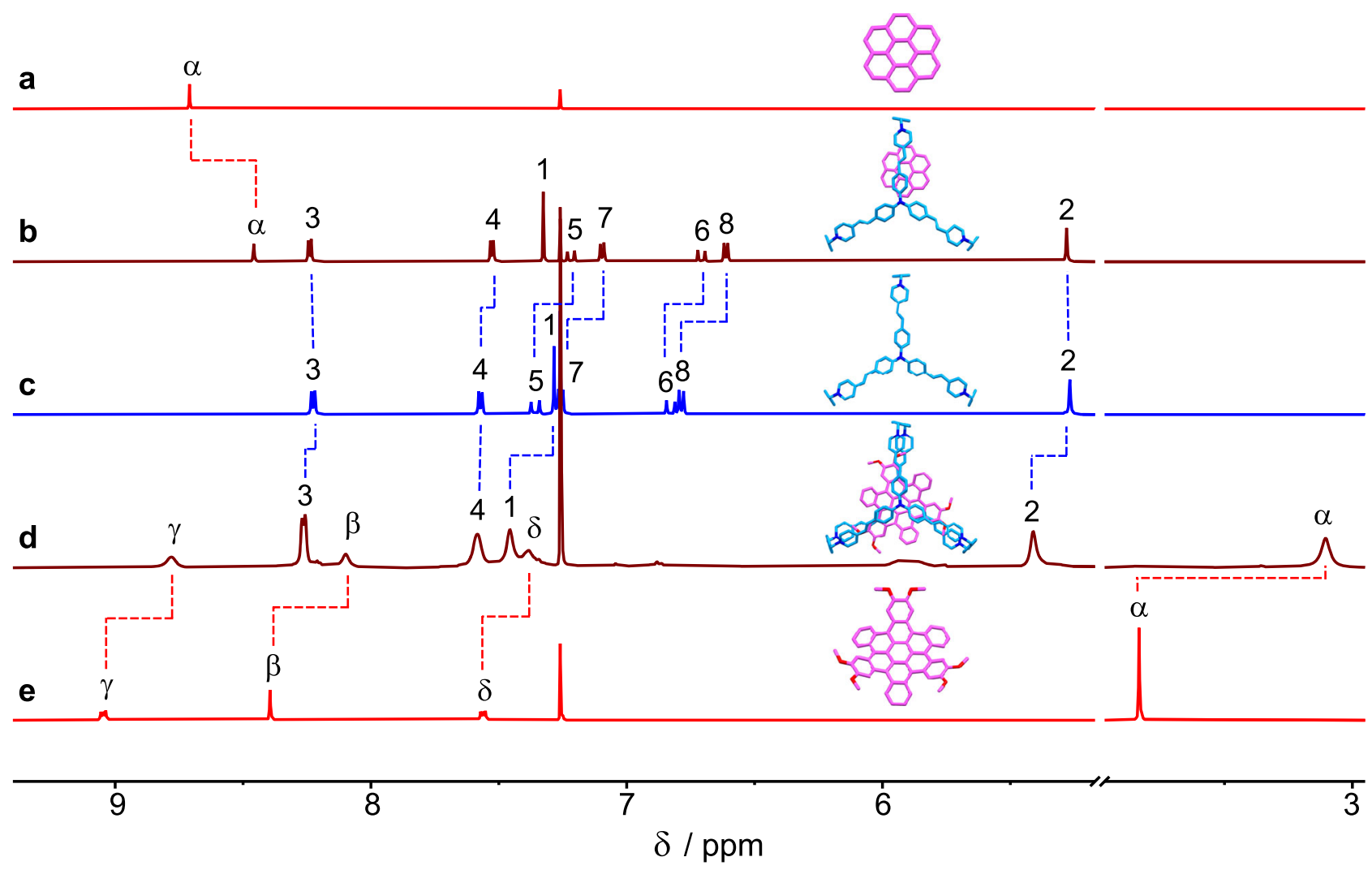

Fig. $4{ }^{1} \mathbf{H}$ NMR Spectroscopic characterization. ${ }^{1} \mathrm{H}$ NMR Spectra $\left(500 \mathrm{MHz}, \mathrm{CD}_{3} \mathrm{CN}: \mathrm{CDCl}_{3}=4: 1,\left[\mathbf{T P A C a g e \bullet}^{6} \mathrm{PF}_{6}\right]=[\mathbf{C O R}]=[\mathbf{3 H}-\mathbf{H B C}]=05.0 \times 10^{-4}\right.$

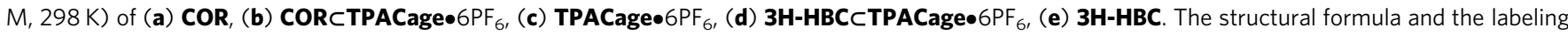
of protons on TPACage $^{6+}$ are defined in Fig. 1, while those for COR and $\mathbf{3 H}-\mathbf{H B C}$ are defined in Fig. 3.

from the fact that the 1,2-dimethoxybenzene rings are located in the cavity formed by pairs of styrene-pyridinium units. The resonances for protons ( $\mathrm{H}-5, \mathrm{H}-6, \mathrm{H}-7$, and $\mathrm{H}-8)$ on the styrene units in TPACage ${ }^{6+}$ display (Fig. 4d) severe broadening, possibly on account of the free pedaling motion about the $\mathrm{C}=\mathrm{C}$ double bonds within the $3 \mathrm{H}-\mathrm{HBC} C$ TPACage ${ }^{6+}$ complex. Protons $\mathrm{H}-1$ and $\mathrm{H}-2$, associated with the $p$-xylylene linkers, exhibit (Fig. $4 \mathrm{~d}$ ) downfield shifts $(\Delta \delta=0.18$ and $0.14 \mathrm{ppm}$ for $\mathrm{H}-1$ and $\mathrm{H}-2$, respectively). In the ${ }^{1} \mathrm{H}$ NMR spectra (Supplementary Fig. 33) of 3Me-HBCCTPACage ${ }^{6+}$ and 3F-HBCCTPACage ${ }^{6+}$, a new set of resonances also appears, accompanied by severe broadening. The resonances for protons $\mathrm{H}-1$ and $\mathrm{H}-2$ attached to the p-xylylene linkers show (Supplementary Fig. 33) characteristic downfield shifts, confirming that $3 \mathrm{Me}-\mathrm{HBC}$ and $3 \mathrm{~F}-\mathrm{HBC}$ are encapsulated by TPACage ${ }^{6+}$. Because of the contorted conformations of the $\boldsymbol{c}$ HBC guests, the association and dissociation of their complexes with TPACage $^{6+}$ undergo (Supplementary Fig. 33) slow exchange on the ${ }^{1} \mathrm{H}$ NMR timescale, in contrast with the fast

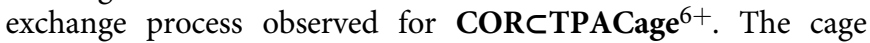
serves as a receptor for both planar COR and contorted $\boldsymbol{c}$-HBC derivatives in the solution state, on account of the relatively flexible conformation and the extensive cavity present in TPACage ${ }^{6+}$.

High-resolution electrospray ionization mass spectrometry (HRESI-MS) also provided strong evidence for the formation of these four host-guest complexes. The monoisotopic masses of the four complexes (Supplementary Figs. 42-45), after deconvolution, were calculated as $2590.56 \mathrm{Da}\left(\mathrm{COR} C \mathrm{TPACage} \cdot 6 \mathrm{PF}_{6}\right), 3070.71 \mathrm{Da}(3 \mathrm{H}-$ HBCCTPACage. $6 \mathrm{PF}_{6}$ ), $3112.77 \mathrm{Da}$ (3Me-HBC $C$ TPACage $6 \mathrm{PF}_{6}$ ), and $3124.70 \mathrm{Da}$ (3F-HBCCTPACage• $6 \mathrm{PF}_{6}$ ), respectively. These values match well with the calculated ones.
UV-Vis absorption and fluorescence spectra of both the cage and guests exhibit marked changes in the formation of host-guest complexes. Upon addition of 1 equiv. of $\boldsymbol{c}$-HBC guests to a MeCN/CHCl 3 (4:1) solution of TPACage ${ }^{6+}$, the characteristic absorption peak (Fig. 5a) of TPACage ${ }^{6+}$ centered on $487 \mathrm{~nm}$ decreases and is accompanied by a redshift. The bright green fluorescence of $\boldsymbol{c}$-HBC guests is almost fully quenched (Fig. 5b), while the fluorescence quantum yields for $3 \mathrm{H}-\mathrm{HBC}, 3 \mathrm{Me}-\mathrm{HBC}$, and 3F-HBC change (Supplementary Table 1) from $3.8 \%$ to $0.6 \%$, $3.7 \%$ to $0.9 \%$, and $3.7 \%$ to $0.3 \%$, respectively. Meanwhile, the emission of $\boldsymbol{c}$-HBC overlaps well (Fig. 5) with the absorption band of TPACage ${ }^{6+}$, enabling potential energy transfer from $c$ HBC to TPACage ${ }^{6+}$. In the UV-Vis absorption of CORCTPACage $^{6+}$, the absorbance at $487 \mathrm{~nm}$ does not change much (Fig. 5a) compared with that of the free TPACage ${ }^{6+}$, because of the low binding affinity $\left(K_{\mathrm{a}}=1.3 \times 10^{3} \mathrm{M}^{-1}\right)$ between COR and TPACage $^{6+}$. By contrast, on adding 4 equiv. of TPACage ${ }^{6+}$ to a solution of COR, the blue fluorescence of COR is almost completely quenched (Fig. 5b) with the fluorescence quantum yield decreasing (Supplementary Table 1) from 1.8 to $0.2 \%$, an observation that can be attributed to (i) the formation of a hostguest complex, and (ii) the strong absorption of the excess of TPACage ${ }^{6+}$ present in the solution.

The changes in the absorption spectra induced by the formation of the host-guest complexes afford us an easy way to track the molecular recognition processes. The Job plots for 3H-HBC (Supplementary Fig. 48), 3Me-HBC (Supplementary Fig. 51), and 3F-HBC (Supplementary Fig. 54) with TPACage ${ }^{6+}$ all show maxima at mole fractions of 0.5 , confirming a stoichiometric ratio of 1:1 for all three complexes. The binding affinities between TPACage $^{6+}$ and the different $c$-HBC guests were determined by 

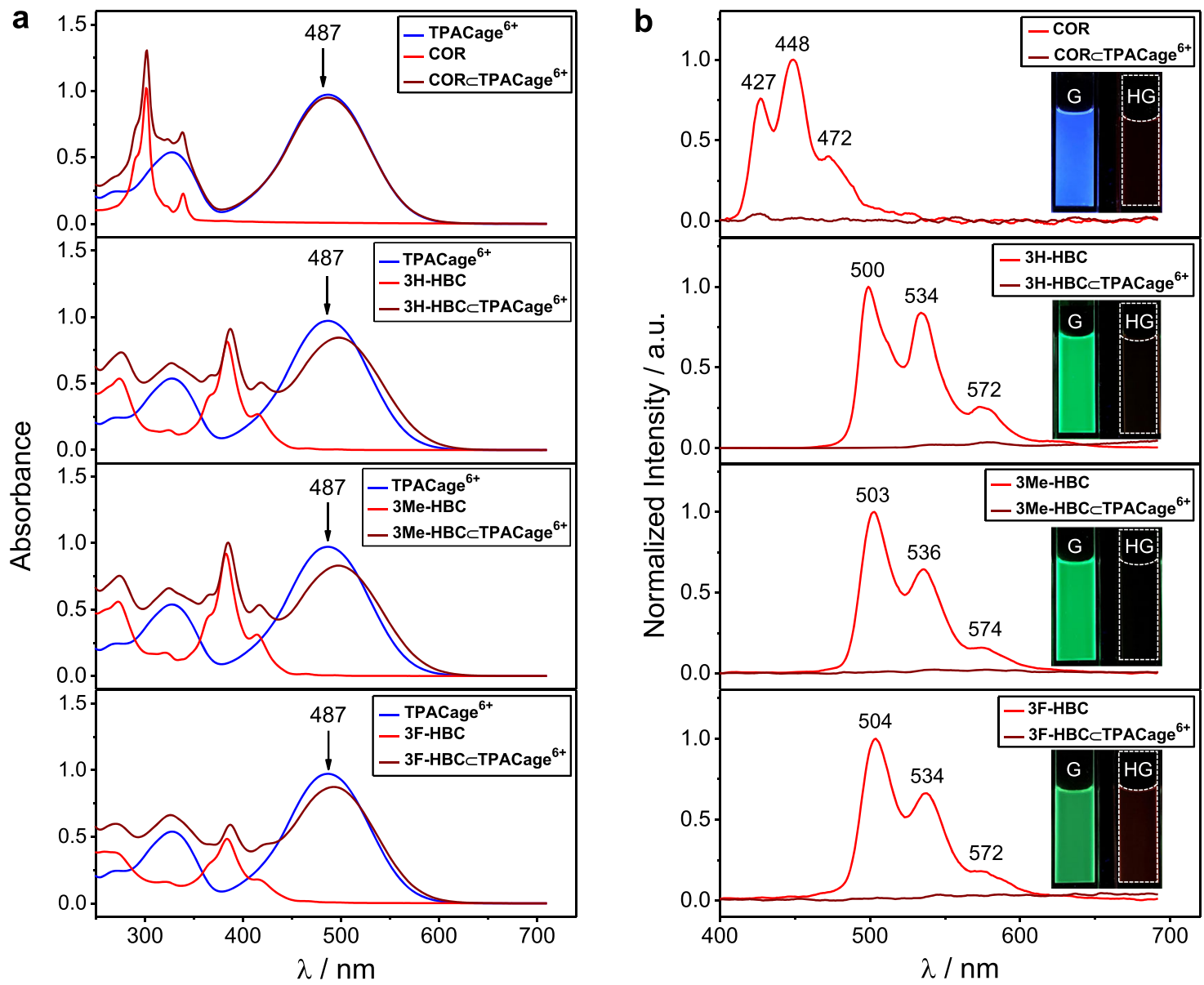

Fig. 5 Photophysical characterization. a UV-Vis Absorption spectra $\left(3 \times 10^{-5} \mathrm{M}, \mathrm{MeCN}: \mathrm{CHCl}_{3}=4: 1,298 \mathrm{~K}\right.$, optical path: $\left.2 \mathrm{~mm}\right)$ of $\mathbf{C O R}$, 3H-HBC, 3Me-

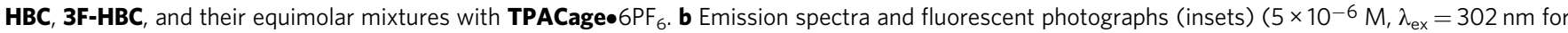
COR/384 nm for C-HBC, MeCN: $\mathrm{CHCl}_{3}=4: 1,298 \mathrm{~K}$ ) of COR, 3H-HBC, 3Me-HBC, and 3F-HBC before (red) and after (brown) adding 4 equiv. of TPACage• $6 \mathrm{PF}_{6}$.

\begin{tabular}{|c|c|c|c|c|c|c|}
\hline Entry & Guest & $K_{\mathrm{a}}\left(M^{-1}\right)$ & $\begin{array}{c}\Delta G \\
\left(k^{\prime}{ }^{-1}\right. \\
\left.\mathrm{mol}^{-1}\right)\end{array}$ & $\begin{array}{c}\Delta H \\
\text { (kcal } \\
\mathrm{mol}^{-1} \text { ) }\end{array}$ & $\begin{array}{c}T \Delta S \\
(k c a l \\
\left.\mathrm{mol}^{-1}\right)\end{array}$ & $\begin{array}{c}\Delta S(\mathrm{cal} \\
\mathrm{mol}^{-1} \\
\left.\mathrm{~K}^{-1}\right)\end{array}$ \\
\hline 1 & COR & $1.3 \times 10^{3}$ & $-4.2^{b}$ & $N D^{d}$ & $\mathrm{ND}^{d}$ & $\mathrm{ND}^{\mathrm{d}}$ \\
\hline 3 & $3 \mathrm{H}-\mathrm{HBC}$ & $1.7 \times 10^{5}$ & $-7.1^{c}$ & $-3.2^{\mathrm{e}}$ & 3.9 & 13.1 \\
\hline 2 & $3 \mathrm{Me}-\mathrm{HBC}$ & $2.4 \times 10^{5}$ & $-7.3^{c}$ & $-3.5^{e}$ & 3.8 & 12.8 \\
\hline 4 & $3 \mathrm{~F}-\mathrm{HBC}$ & $8.0 \times 10^{4}$ & $-6.7^{c}$ & $-2.4^{e}$ & 4.3 & 14.4 \\
\hline
\end{tabular}

aStandard errors are presented in the Supplementary Information. b Estimated from $1 \mathrm{H}$ NMR titrations. CEstimated from UV-Vis titrations. ${ }^{\text {NNot determined. }}$ e Directly determined by ITC.

UV-Vis titrations. The $K_{\mathrm{a}}$ value for the $3 \mathrm{H}-\mathrm{HBCCTPACage} \mathrm{e}^{6+}$ complex was determined (Supplementary Fig. 47) to be $1.7 \times 10^{5} \mathrm{M}$ ${ }^{-1}$ by following the change in absorbance at $487 \mathrm{~nm}$. The Gibbs free energy $(\Delta G)$ was calculated (Table 1$)$ to be $-7.1 \mathrm{kcal} \mathrm{mol}^{-1}$, a value which is more negative than that $\left(-4.2 \mathrm{kcal} \mathrm{mol}^{-1}\right)$ for COR $\subset$ TPACage $^{6+}$ complex. It follows that the better the size matching between the host and guests, the stronger are the binding affinities. Because of the poor solubility of $\mathbf{3 H}-\mathbf{H B C}$ in $\mathrm{MeCN} /$ $\mathrm{CHCl}_{3}(4: 1)$, it is difficult to obtain the $K_{\mathrm{a}}$ value for the $\mathbf{3 H}$ HBCCTPACage $^{6+}$ complex using isothermal titration calorimetry (ITC). The change in enthalpy $(\Delta H)$ on complexing $3 \mathbf{H}-\mathbf{H B C}$ within TPACage ${ }^{6+}$ was estimated (Supplementary Fig. 62) to be $-3.2 \mathrm{kcal} \mathrm{mol}^{-1}$ from an isotherm obtained from a single injection experiment ${ }^{63}$. The value of $T \Delta S$ was calculated (Table 1) to be $3.9 \mathrm{kcal} \mathrm{mol}^{-1}$, while the change in entropy $(\Delta S)$ is $13.1 \mathrm{cal} \mathrm{mol}^{-1}$ $\mathrm{K}^{-1}$. The increase in the entropy upon forming the $3 \mathbf{H}$ HBCCTPACage $^{6+}$ complex can be attributed most likely to the desolvation of the guest and the expulsion of solvent molecules originally residing inside the cavity of the TPACage ${ }^{6+}$, a phenomenon similar to that observed in previous reports ${ }^{57,64}$. Using the same procedures, the $K_{\mathrm{a}}$ values for the $3 \mathrm{Me}$ HBCCTPACage $^{6+}$ (Supplementary Fig. 50) and the 3FHBCCTPACage $^{6+}$ (Supplementary Fig. 53) complexes were determined to be $2.4 \times 10^{5}$ and $8.0 \times 10^{4} \mathrm{M}^{-1}$, respectively. The $\Delta H$ values for the formation of 3 Me-HBCCTPACage ${ }^{6+}$ (Supplementary Fig. 63) and 3F-HBCCTPACage ${ }^{6+}$ (Supplementary Fig. 64) were estimated to be -3.5 and $-2.4 \mathrm{kcal} \mathrm{mol}^{-1}$ by ITC, and the corresponding $T \Delta S$ values were calculated to be 3.8 and $4.3 \mathrm{kcal} \mathrm{mol}^{-1}$, respectively. It follows that the formation of the $c$ HBCCTPACage $^{6+}$ complexes is driven collectively by favorable entropy and enthalpy changes. The binding constants and enthalpy changes between the $\boldsymbol{c}$-HBC guests and TPACage ${ }^{6+}$ are arranged in the order $\mathbf{3 M e}-\mathbf{H B C}>\mathbf{3 H}-\mathbf{H B C}>\mathbf{3 F}-\mathbf{H B C}$, indicating that, as the electron density of the guests increases, the binding affinities between the host and guests become stronger in the solution state. The kinetics associated with the encapsulations of the $\boldsymbol{c}$-HBC guests by the TPACage ${ }^{6+}$ can be obtained ${ }^{63}$ by following the change in absorbance with time. The association rate constants 

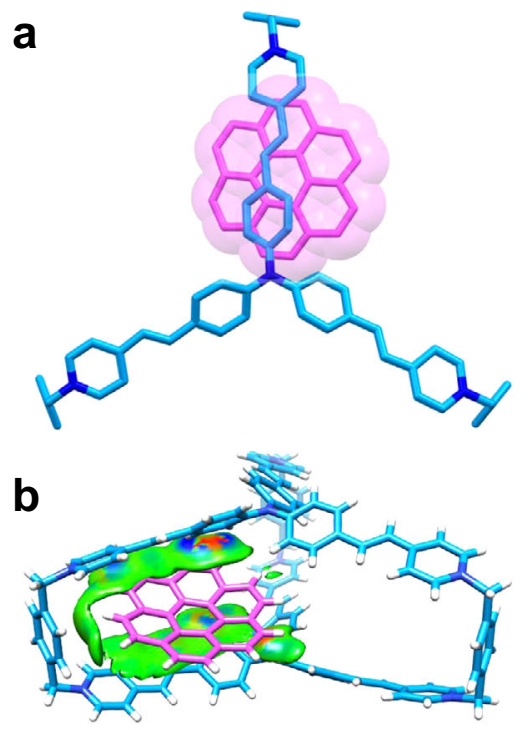

C

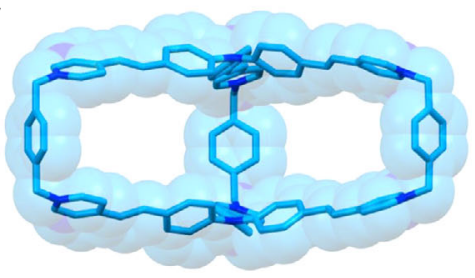

d
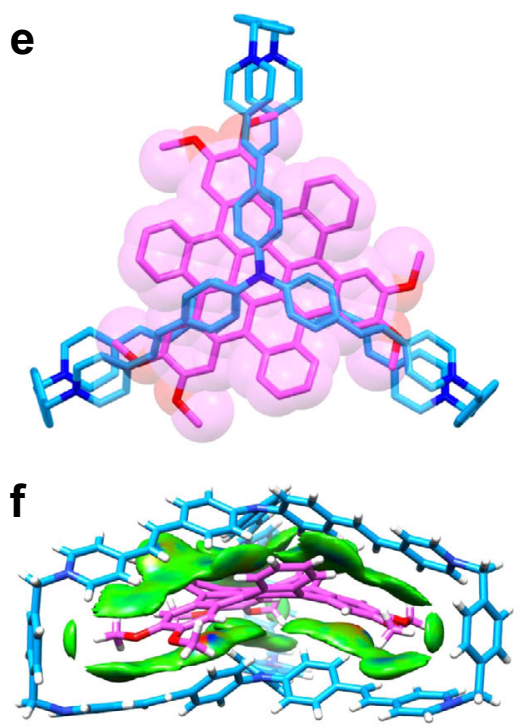

g

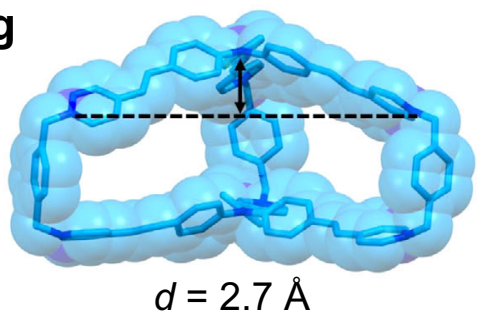

h

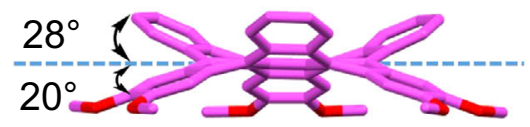

i
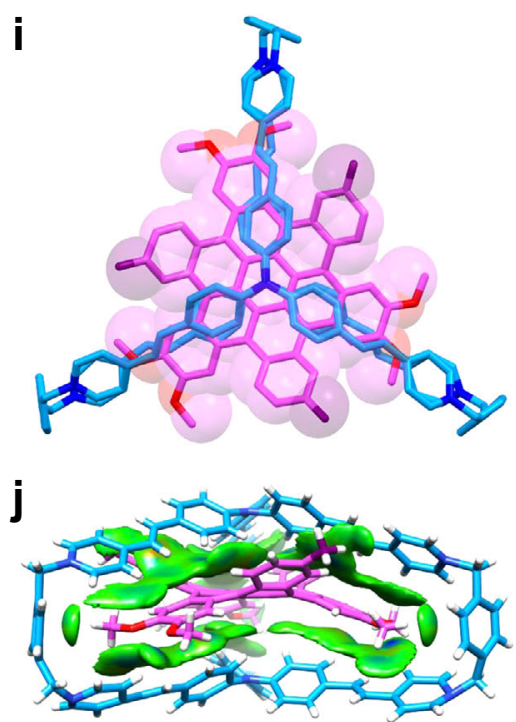

k

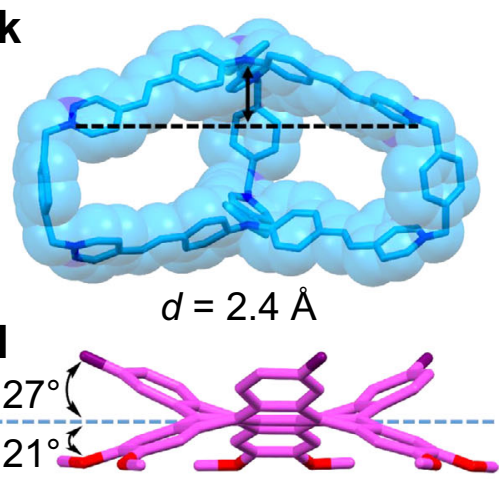

Fig. 6 Solid-state superstructures of the host-guest complexes. a, b Capped-stick and space-filling representations of the solid-state superstructure and the intermolecular binding iso-surface of COR $\subset$ TPACage ${ }^{6+} . \mathbf{c}, \mathbf{d}$ Capped-stick and space-filling representations of the corresponding solid-state structures of individual TPACage ${ }^{6+}$ and $\mathbf{C O R}$ molecules in their 1:1 complex. e, $\mathbf{f}$ Capped-stick and space-filling representations of the solid-state superstructure and intermolecular binding iso-surface of $\mathbf{3 H}-\mathbf{H B C} \subset \mathbf{T P A C a g e}^{6+} . \mathbf{g}, \mathbf{h}$ Capped-stick and space-filling representations of the corresponding solid-state structures of individual TPACage ${ }^{6+}$ and $\mathbf{3 H}-\mathbf{H B C}$ molecules in their 1:1 complex, showing the characteristic parameters defining the changes in their geometries. $\mathbf{i}$, $\mathbf{j}$ Capped-stick and space-filling representations of the solid-state superstructure and intermolecular binding iso-surface of $\mathbf{3}$ Me-HBC $\subset$ TPACage ${ }^{6+}$. $\mathbf{k}$, I Capped-stick and space-filling representations of the corresponding solid-state structures of individual TPACage ${ }^{6+}$ and $\mathbf{3 M e - H B C}$ molecules in their 1:1 complex, showing the characteristic parameters defining the changes in their geometries. Solvent molecules and counterions have been omitted for the sake of clarity. $\mathrm{C}$ skyblue, pink and purple, $\mathrm{H}$ white, $\mathrm{O}$ red, $\mathrm{N}$ blue.

$\left(k_{\text {on }}\right)$ for TPACage ${ }^{6+}$ with $3 \mathrm{H}-\mathrm{HBC}, 3 \mathrm{Me}-\mathrm{HBC}$, and $3 \mathrm{~F}-\mathrm{HBC}$ were found (Supplementary Figs. 59-61) to be $7.2 \times 10^{6}, 2.6 \times 10^{6}$, and $3.2 \times 10^{6} \mathrm{M}^{-1} \mathrm{~s}^{-1}$, respectively. These $k_{\mathrm{on}}$ values indicate that, as the size of the guests increases, the rates of association between the TPACage ${ }^{6+}$ and the $c$-HBC guests decrease.

Solid-state superstructures of the host-guest complexes. In order to elucidate the binding modes of TPACage ${ }^{6+}$ toward COR $^{-1}$ and $\boldsymbol{c}$-HBC guests in the solid state, their complexes were analyzed by single-crystal X-ray diffraction. Dark red single crystals of the 1:1 complex between TPACage ${ }^{6+}$ and COR were obtained by slow vapor diffusion of $i \mathrm{Pr}_{2} \mathrm{O}$ into $\mathrm{MeOH} / \mathrm{CHCl}_{3}$ (4:1) solution of TPACage $6 \mathrm{Cl}$ containing an excess of $\mathbf{C O R}$ over a period of three days. Single-crystal X-ray diffraction analysis revealed that the COR is positioned (Fig. $6 \mathrm{a}$ ) closer to one of the $p$-xylylene linkers in TPACage ${ }^{6+}$, rather than in the center of the cavity. Independent gradient model (IGM) analysis revealed that (Fig. 6b) the binding mode is sustained by $[\pi \cdots \pi]$ interactions between the electron-rich COR and the electron-deficient pyridinium units on the side of the cage, as well as by a $[\mathrm{C}-\mathrm{H} \cdots \pi]$ interaction between a hydrogen atom on COR and the nearby $p$-xylylene linker with a distance of $3.1 \AA$. Notably, the COR guest is disordered (Supplementary Fig. 65) among six different positions with an average occupation of one-sixth in the cavity of the cage. The COR guest is not only able to reside (Supplementary Fig. 65a) in any one of three slots formed by three pairs of styrene-pyridinium units, but it also occupies (Supplementary Fig. 65b) two positions in each slot. These observations indicate that COR is not large enough to occupy the entire cavity in the cage.

Single crystals of 3 H-HBCCTPACage ${ }^{6+}$ complex were obtained after numerous attempts by slow vapor diffusion of $i \mathrm{Pr}_{2} \mathrm{O}$ into $\mathrm{MeNO}_{2} / \mathrm{CHCl}_{3}$ (4:1) solution containing equimolar amounts of TPACage $6 \mathrm{AsF}_{6}$ and $3 \mathbf{H}-\mathbf{H B C}$ over three days. In the solid-state superstructure of $3 \mathbf{H}-\mathbf{H B C \subset T P A C a g e}{ }^{6+}, 3 \mathbf{H}-$ HBC is located (Fig. 6e) in the center of the cavity inside TPACage $^{6+}$, forming a $C_{3}$-symmetrical host-guest complex. Three 1,2-dimethoxybenzene groups in $\mathbf{3 H}$-HBC are located in the slots defined by three pairs of styrene-pyridinium units, which are stabilized by intermolecular $[\pi \cdots \pi]$ and $[\mathrm{C}-\mathrm{H} \cdots \pi]$ interactions with average distances of $3.7 \AA$ and $3.2 \AA$, respectively. The outer benzenoid rings in $3 \mathbf{H}-\mathbf{H B C}$ reside in the spaces between two 


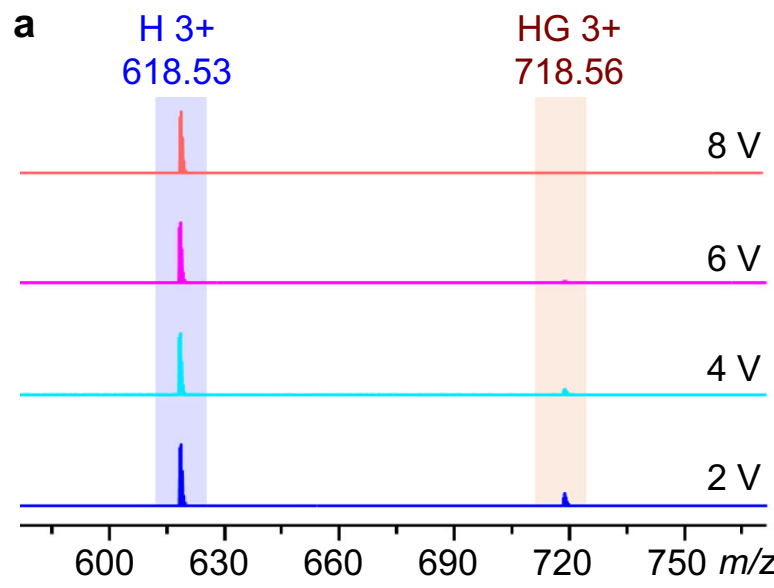

b $\quad \mathrm{H} 3+$

618.53
HG 3+

878.61
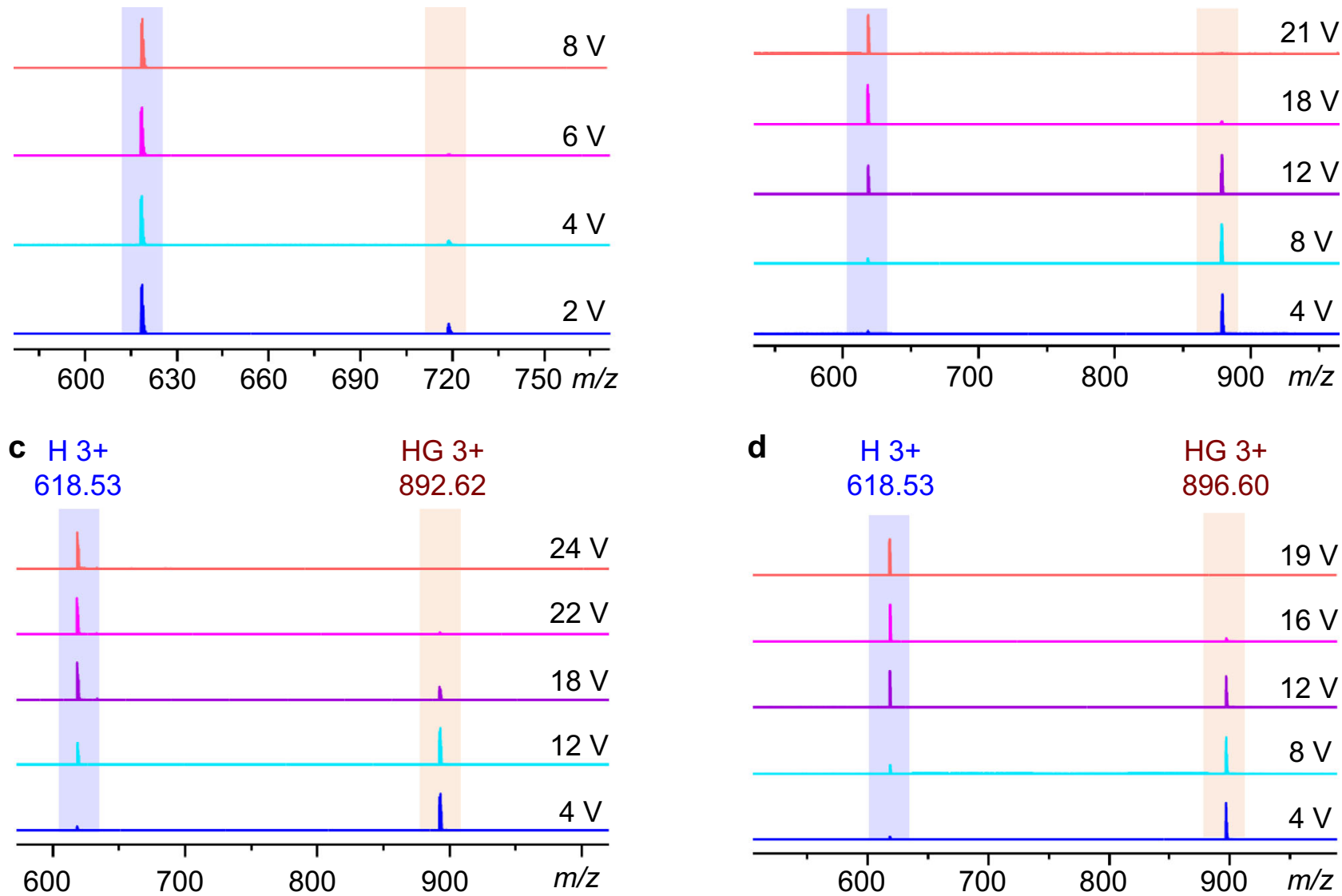

d $\mathrm{H} 3+$ 618.53

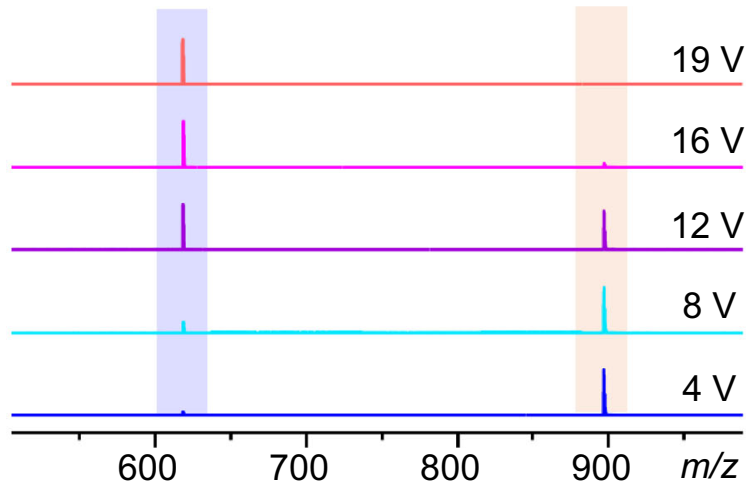

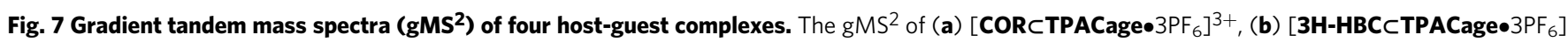
$3+,(\mathbf{c})\left[\mathbf{3 M e}-\mathbf{H B C} \subset \mathbf{T P A C a g e \bullet} 3 \mathrm{PF}_{6}\right]^{3+}$, and $(\mathbf{d})\left[\mathbf{3 F}-\mathbf{H B C} \subset \mathbf{T P A C a g e \bullet} 3 \mathrm{PF}_{6}\right]^{3+}$, showing that the signal intensity for complexes gradually decreases as the voltage is increased. Blue "H 3+" represents the three positively charged states of the free TPACage•6PF 6 , while brown "HG 3+" represents the three positively charged states of the host-guest complexes.

styrene-pyridinium units in the cage. The reasons for this particular binding mode are (i) the $[\mathrm{C}-\mathrm{H} \cdots \pi]$ interaction (Fig. 6f) between the hydrogens attached to methoxy groups on the $3 \mathbf{H}$ HBC and $p$-xylylene linkers of the cage, and (ii) the fact that 1,2dimethoxybenzene groups are (Fig. 3f) more electron-rich than the outer benzenoid rings in $\mathbf{3 H}-\mathbf{H B C}$. The conformation of $\mathbf{3 H}$ HBC undergoes (Fig. 6h) remarkable changes following inclusion inside the cavity of TPACage ${ }^{6+}$. The average tilt angle between the 1,2-dimethoxybenzene groups and the central benzene ring is $20^{\circ}$, while that between the outer benzenoid rings and the central benzene ring is $28^{\circ}$. These two tilt angles are different from those (26 and $24^{\circ}$ ) in the free $3 \mathbf{H}-\mathbf{H B C}$ (Fig. 3e), on account of the tight encapsulation of $3 \mathbf{H}-\mathbf{H B C}$ by TPACage ${ }^{6+}$. The additional strain energy for $\mathbf{3 H}$-HBC in the host-guest complex is (Supplementary Table 4) $2.1 \mathrm{kcal} \mathrm{mol}^{-1}$ according to DFT calculations. The TPACage $^{6+}$ also becomes deformed in order to accommodate the twisted geometry of $\mathbf{3 H}-\mathbf{H B C}$. It changes (Fig. $6 \mathrm{~g}$ ) to a yurtlike shape, in which one of the TPAP units bulges outwards. These observations are reminiscent of the induced fit of enzymes with respect to their substrates in biological systems ${ }^{65,66}$.

Using the same procedure, the crystal superstructure of $3 \mathbf{M e}-$ HBCCTPACage $^{6+}$ was obtained. The binding mode (Fig. 6i-6l) of $3 \mathrm{Me}-\mathrm{HBC}$ inside the cavity of TPACage ${ }^{6+}$ is almost the same as that of $\mathbf{3 H}-\mathbf{H B C}$, indicating that the yurt-like binding mode of complexes is thermodynamically stable in the solid state. The 3Me-HBC guest also undergoes distortion within the cavity of
TPACage $^{6+}$. Its strain energy is (Supplementary Table 4) $2.3 \mathrm{kcal} \mathrm{mol}^{-1}$, a value which is close to that $\left(2.1 \mathrm{kcal} \mathrm{mol}^{-1}\right)$ of 3H-HBC in its host-guest complex.

Gas-phase stability of the host-guest complexes. In addition, the stability of these four complexes in the gas phase was investigated indepth by gradient tandem mass spectrometry $\left(\mathrm{gMS}^{2}\right)$. The $3+$ peaks

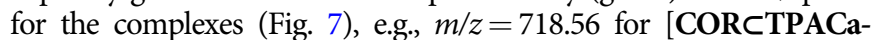

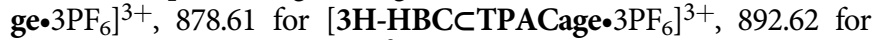
$\left[3 \mathrm{Me}-\mathrm{HBCCTPACage} \cdot 3 \mathrm{PF}_{6}\right]^{3+}$, and 896.60 for [3F-HBCCTPACage. $\left.3 \mathrm{PF}_{6}\right]^{3+}$, were selected as parent ions, which were isolated using a quadrupole, followed by disintegration in the trap cell through collision-induced dissociation (CID) while the trap voltage was gradually increased. As the voltages increase, the signal intensities for the complexes gradually decrease (Fig. 7), accompanied by the generation of a peak at $m / z=618.53$, which can be assigned to the free $\left[\mathrm{TPACage} \cdot 3 \mathrm{PF}_{6}\right]^{3+}$. The $\left[3 \mathrm{Me}-\mathrm{HBC} \subset \mathrm{TPACage} \cdot 3 \mathrm{PF}_{6}\right]^{3+}$ complex dissociates (Fig. 7c) fully at a trap voltage of $24 \mathrm{~V}$, corresponding to a center-of-mass collision energy of $1.06 \mathrm{eV}$, which is the highest one among the four complexes. In sharp contrast, the $\left[\mathrm{COR} \subset \mathrm{TPACage} \cdot 3 \mathrm{PF}_{6}\right]^{3+}$ complex dissociates (Fig. 7a) completely at a low trap voltage of $8 \mathrm{~V}$, corresponding to a center-ofmass collision energy of $0.44 \mathrm{eV}$. The collision energies for dissociating the $\left[3 \mathrm{H}-\mathrm{HBCCTPACage} \cdot 3 \mathrm{PF}_{6}\right]^{3+}$ (Fig. $\left.7 \mathrm{~b}\right)$ and [3F-HBCCTPACage. $\left.3 \mathrm{PF}_{6}\right]^{3+}$ (Fig. $7 \mathrm{~d}$ ) complexes were calculated to 

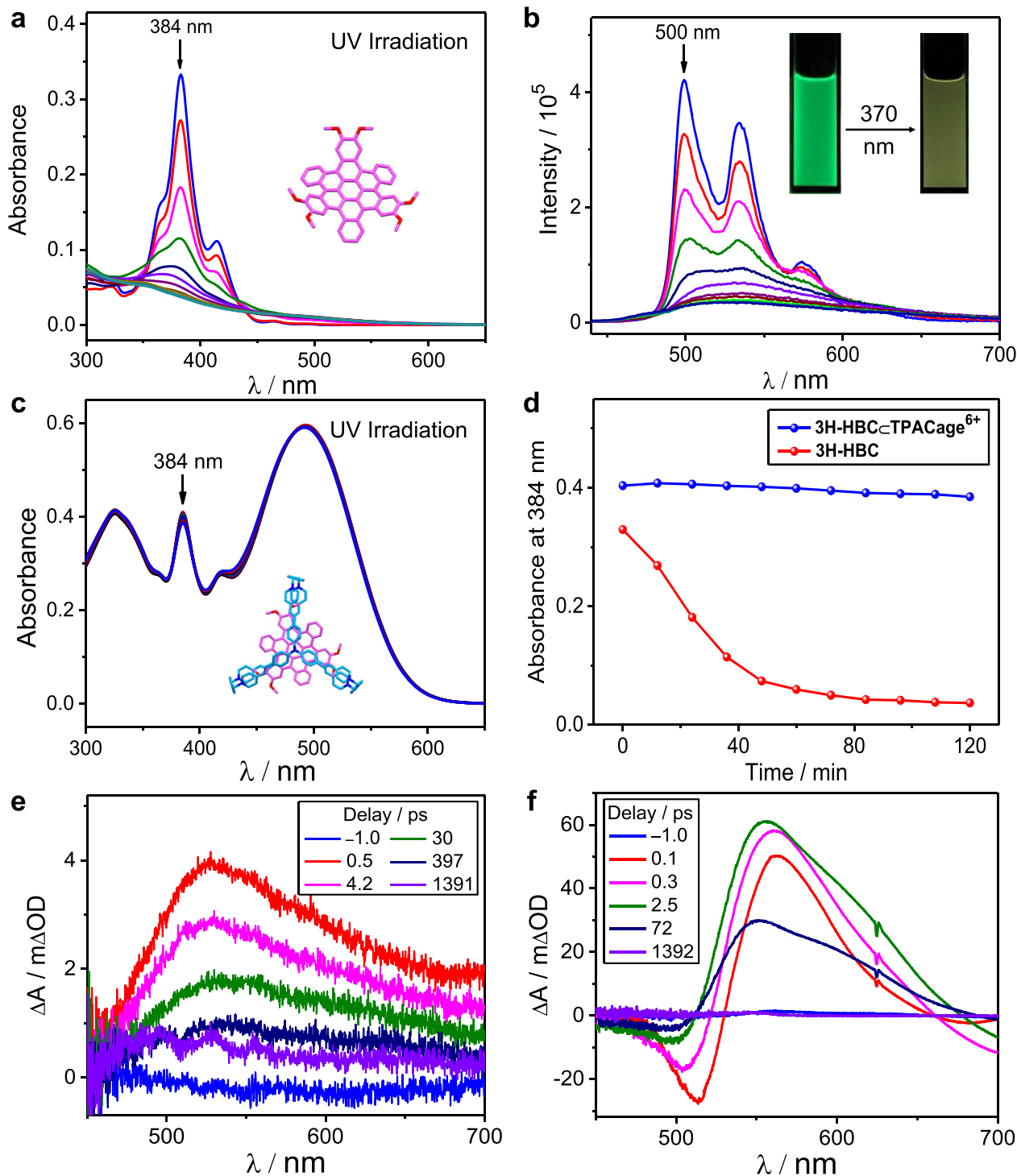

Fig. 8 Investigation of photostability. a Changes in UV -Vis absorption spectra of $\mathbf{3 H}-\mathbf{H B C}$ upon irradiation with UV light ( $370 \mathrm{~nm}, 120 \mathrm{~min}$ ). $\mathbf{b}$ Changes in emission spectra $\left(\lambda_{\mathrm{ex}}=384 \mathrm{~nm}\right)$ and fluorescent photographs (inset) of $\mathbf{3 H}-\mathbf{H B C}$ upon irradiation with UV light ( $\left.370 \mathrm{~nm}, 120 \mathrm{~min}\right)$. c Changes in UV-Vis absorption spectra of $\mathbf{3 H}$-HBC $\subset$ TPACage $6 \mathrm{PF}_{6}$ upon irradiation with UV light ( $370 \mathrm{~nm}, 120 \mathrm{~min}$ ). $\mathbf{d}$ Changes in absorbance at $384 \mathrm{~nm}$ of $\mathbf{3 H}$-HBC (red) and $\mathbf{3 H}-\mathbf{H B C} \subset \mathbf{T P A C a g e \bullet} 6 \mathrm{PF}_{6}$ (blue) upon irradiation with UV light (370 nm, $120 \mathrm{~min}$ ). Femtosecond transient absorption spectra of (e) $\mathbf{3 H}-\mathbf{H B C}$ excited at $350 \mathrm{~nm}$, and (f) $\mathbf{3 H}-\mathbf{H B C} \subset \mathbf{T P A C a g e \bullet} 6 \mathrm{PF}_{6}$ excited at $350 \mathrm{~nm}$.

be $0.94 \mathrm{eV}$ and $0.83 \mathrm{eV}$, respectively. The stability of the four complexes in the gas phase can be ranked $\mathbf{3 M e - H B C}>\mathbf{3 H}-\mathbf{H B C}>\mathbf{3 F}$ $\mathrm{HBC} \gg \mathrm{COR}$ according to the collision energies, a trend which is consistent with the order of binding constants (Table 1) obtained in solution.

DFT calculations. In order to probe the origins of the changes in photophysical properties and gain insights into the electronic properties of these four host-guest complexes, density functional theory (DFT) calculations were performed. The optimized super-

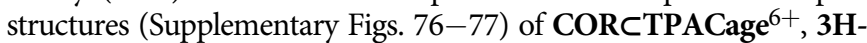
HBCCTPACage $^{6+}$, and 3Me-HBCᄃTPACage ${ }^{6+}$ are good matches with those obtained from single-crystal X-ray diffraction. Frontier molecular orbital (FMO) analyses show (Supplementary Fig. 76a) that both the highest occupied molecular orbital (HOMO) and lowest unoccupied molecular orbital (LUMO) of CORCTPACage $^{6+}$ complex are localized on TPACage ${ }^{6+}$, a situation which is different from the FMOs (Supplementary Figs. 76-77) for the complexes between the TPACage ${ }^{6+}$ and $\boldsymbol{c}$-HBC guests. The
HOMOs for the $\boldsymbol{c}$-HBCCTPACage ${ }^{6+}$ complexes are localized predominantly on the $\boldsymbol{c}$-HBC guests, while the LUMOs are confined mainly to TPACage ${ }^{6+}$. The HOMO-LUMO energy gaps in MeCN (Supplementary Table 3) for the COR, 3H-HBC, 3Me-HBC and 3F-HBC guests, and TPACage ${ }^{6+}$ host are 4.07, 3.22, 3.20, 3.19, and $2.48 \mathrm{eV}$, respectively, while their corresponding host-guest complexes possess contracted energy gaps with the values of 2.44, 2.30, 2.24 , and $2.32 \mathrm{eV}$, respectively. These narrowed energy gaps provide the internal reason for the red-shifted absorption spectra in the case of both the host and guests upon forming complexes. Electrostatic potential analyses revealed that the electron density in the original electron-rich guests decreases sharply (Supplementary Figs. 79-80) following complexation by TPACage ${ }^{6+}$, suggesting the presence of the intermolecular electron delocalization. The host-guest binding energies were also estimated by DFT calculations. The calculated binding energies in vacuum (Supplementary Table 5) between TPACage $^{6+}$ and four different guests are arranged in the order of $\mid$ $\Delta E_{3 \mathrm{Me}-\mathrm{HBC}}|>| \Delta E_{3 \mathrm{H}-\mathrm{HBC}}|>| \Delta E_{3 \mathrm{~F}-\mathrm{HBC}}|\gg| \Delta E_{\mathrm{COR}} \mid$, a trend which is consistent with the sequence of Gibbs free energies in Table 1. 
Guest protection within the cage. Upon exposing a $3 \mathrm{H}-\mathrm{HBC}$ suspension to UV light $(370 \mathrm{~nm})$, we found, quite accidentally, that the suspension turned into a clear solution. In order to gain a better understanding of this phenomenon, UV-Vis absorption and fluorescence spectroscopic measurements were carried out. Upon irradiation of a $0.5 \mathrm{mM} 3 \mathbf{H}-\mathbf{H B C}$ solution with UV light $(370 \mathrm{~nm})$, the UV-Vis absorption spectra of its dilute solution revealed that the absorption peak centered on $384 \mathrm{~nm}$ decreases gradually (Fig. 8a). After irradiation for $120 \mathrm{~min}$, the UV-Vis absorption spectrum no longer undergoes any change, and the absorbance at $384 \mathrm{~nm}$ is decreased (Fig. $8 \mathrm{~d}$ ) by $89 \%$. During the irradiation, no obvious new peak appears in the UV-Vis absorption spectra, indicating that the $\mathbf{3 H}-\mathbf{H B C}$ may be undergoing degradation when exposed to UV light. The fluorescence of 3H-HBC also decreases dramatically (Fig. 8b), and its bright green fluorescence turns to a pale yellow when exposed to UV light for $120 \mathrm{~min}$. These observations confirm the photodegradation process of $3 \mathbf{H}-\mathbf{H B C}$. Upon adding 2 equiv. of TPACage ${ }^{6+}$ to a $\mathrm{MeCN} / \mathrm{CHCl}_{3}(4: 1)$ solution containing $0.5 \mathrm{mM}$ $3 \mathbf{H}-\mathbf{H B C}$, we estimate that $99 \%$ of the $3 \mathbf{H}-\mathbf{H B C}$ guest is encapsulated inside the cavity of the cage according to the association and disassociation equilibria. When this solution is irradiated with UV light $(370 \mathrm{~nm})$ for $120 \mathrm{~min}$, the UV-Vis absorption spectra of its dilute solution show (Fig. 8c) slight changes. The characteristic absorption peak of $3 \mathbf{H}-\mathbf{H B C}$ at $384 \mathrm{~nm}$ decreases (Fig. $8 \mathrm{~d}$ ) by only $4.7 \%$. Similarly, when solutions of $3 \mathrm{Me}-$ HBCCTPACage $^{6+}$ and 3F-HBCCTPACage ${ }^{6+}$ are irradiated with UV light $(370 \mathrm{~nm}, 120 \mathrm{~min})$, the characteristic absorption peak of the $3 \mathrm{Me}-\mathrm{HBC}$ guest at $384 \mathrm{~nm}$ decreases (Supplementary Figs. $83-84$ ) by $8.4 \%$, while the absorbance of the 3F-HBC guest at $384 \mathrm{~nm}$ shows no appreciable decline (Supplementary Figs. 85-86). It follows that the TPACage ${ }^{6+}$ acts as a protective shield, reducing the photo-degradation rates of the $\boldsymbol{c}$-HBC guests to a considerable degree. When the irradiation times for the hostguest complexes were extended to $240 \mathrm{~min}$, the characteristic absorption peaks of $\mathbf{3 H}-\mathbf{H B C}$ and $3 \mathrm{Me}-\mathrm{HBC}$ at $384 \mathrm{~nm}$ decreased (Supplementary Fig. 87 ) by 13.7 and $15.7 \%$, respectively, while the absorbance of $\mathbf{3 F}-\mathbf{H B C}$ at $384 \mathrm{~nm}$ exhibited very little change (Supplementary Fig. 87). The slow photo-degradation of the $\boldsymbol{c}$ HBC guests after long periods of irradiation can be attributed to the dynamic and reversible nature of the host-guest complexes and the slight photodamage of the host. Possible reasons for the difference in the photo-degradation rate between the three $\boldsymbol{c}$-HBC guests in the host-guest complexes could be the fact that (i) the different guests display (Supplementary Figs. 59-61) different association/dissociation binding kinetics toward the TPACage ${ }^{6+}$, and (ii) the intrinsic photostability of the three guests is different (Supplementary Figs. 88-89). The good photostability of the 3FHBCCTPACage $^{6+}$ complex may result from the relatively slow photolysis rate of the $3 \mathrm{~F}-\mathrm{HBC}$, and ideal association/dissociation exchange kinetics of the 3F-HBCCTPACage ${ }^{6+}$ complex in solution.

In order to ascertain the underlying mechanism giving rise to the additional photostability of $\boldsymbol{c}$-HBC provided by encapsulation within TPACage ${ }^{6+}$, femtosecond transient absorption (fsTA) measurements were carried out to probe the photo-induced dynamics of $\mathbf{3 H}-\mathbf{H B C}$ and $\mathbf{3 H}-\mathbf{H B C} C$ TPACage ${ }^{6+}$ complex. The fsTA spectra of $\mathbf{3 H}-\mathbf{H B C}$ exhibit (Fig. 8e) a broad excited-state absorption feature at $525 \mathrm{~nm}$ when excited with a 350-nm pump pulse. Global analysis reveals (Supplementary Fig. 91) that the singlet excited-state $\left(S_{1}\right)$ lifetime of $3 \mathbf{H}-\mathbf{H B C}$ is $\sim 100 \mathrm{ps}$, preceded by a 6.2-ps relaxation attributed to vibrational relaxation within the initial $S_{1}$ excited state. The fsTA spectra of TPACage ${ }^{6+}$ show (Supplementary Fig. 90a) a strong excited-state absorption transition centered at $560 \mathrm{~nm}$ upon excitation of its main absorption peak at $500 \mathrm{~nm}$. When exciting the $\mathbf{3 H}$ -
HBCCTPACage $^{6+}$ at $350 \mathrm{~nm}$, its fsTA spectra (Fig. 8f) do not show the $S_{1}$ excited-state signature of $3 \mathbf{H}-\mathbf{H B C}$, while only the spectral features of the TPACage ${ }^{6+}$ are immediately observed. The excited-state dynamics of $3 \mathbf{H}$-HBCCTPACage ${ }^{6+}$ (Fig. $8 \mathrm{f}$ and Supplementary Fig. 92) are analogous to those of the free TPACage $^{6+}$ (Supplementary Fig. 90) excited at $500 \mathrm{~nm}$, and lacking the 6.2-ps relaxation of $3 \mathbf{H}-\mathbf{H B C}$. These observations suggest the presence of ultrafast energy transfer from $\mathbf{3 H}-\mathbf{H B C}$ to TPACage $^{6+}$ upon excitation of the $3 \mathrm{H}-\mathrm{HBCCTPACage}{ }^{6+}$ complex, and the cage acts to quench the excited state of $3 \mathbf{H}-$ HBC in this process. The corresponding timescale of the energy transfer is estimated to be $<0.3$ ps (the fsTA instrument time resolution), a value which is much less than the excited-state lifetime (100 ps) of the free $\mathbf{3 H}-\mathbf{H B C}$. This ultrafast deactivation pathway (Supplementary Fig. 93) of the $\mathbf{3 H}-\mathbf{H B C} \mathrm{S}_{1}$ excited state can suppress significantly the photo-induced degradation of $\mathbf{3 H}$ HBC in the excited state. Consequently, the photostability of the $\boldsymbol{c}$-HBC guests is enhanced on complexation inside the cavity of the TPACage ${ }^{6+}$.

\section{Discussion}

A trigonal prismatic hexacationic cage, TPACage ${ }^{6+}$, with a welldefined cavity and a relatively flexible conformation, has been designed and synthesized. The cage is able to encapsulate both planar coronene and contorted hexabenzocoronene guests with favorable changes in both enthalpy and entropy. As a result of the ideal dimensional matching, the binding affinities between the TPACage $^{6+}$ and the contorted hexabenzocoronene guests are larger than that in the case of coronene. To the best of our knowledge, the contorted hexabenzocoronene is the largest nanographene guest which has been investigated in the context of host-guest chemistry. Encapsulating the contorted hexabenzocoronene inside the cage, not only enriches host-guest chemistry ${ }^{67,68}$ but also extends the potential applications of synthetic receptors when it comes to the separation and stabilization of nanographenes. It is worthy of note that, benefiting from the ultrafast deactivation of the excited state of the hexabenzocoronene by transferring energy to the TPACage ${ }^{6+}$, the photostability of the hexabenzocoronene guests is improved significantly. Enhancing the photostability of the $c$-HBCСTPACage $^{6+}$ complexes constitutes a good example of regulating the photo-reaction pathway in nanographenes by a non-covalent strategy. We anticipate these complexes will serve as promising building blocks for the construction of nanographene-based mechanically interlocked molecules ${ }^{69}$ and new kinds of photostable synthetic materials 64,70 that combine the properties of graphene derivatives and wholly synthetic receptors.

\section{Methods}

Materials. All reagents were purchased from commercial suppliers and used without further purification unless stated otherwise. The synthesis of TPACage ${ }^{6+}$ is shown in Supplementary Figs. 1-3. Coronene, defined as COR, was purchased from Sigma-Aldrich. The hexa-cata-hexabenzocoronene guests, defined as $\boldsymbol{c}$-HBC, were prepared according to the literature procedure with some modifications as shown in Supplementary Fig. 4.

NMR measurements. NMR spectra were recorded on a Bruker Avance III $600 \mathrm{MHz}$, Agilent $500 \mathrm{MHz}$, and Bruker Avance III $400 \mathrm{MHz}$ spectrometers in $\mathrm{CD}_{3} \mathrm{CN}, \mathrm{CDCl}_{3}, \mathrm{CD}_{3} \mathrm{OD}$ or their mixed solvents, with working frequencies of 600 , 500 , and $400 \mathrm{MHz}$ for recording ${ }^{1} \mathrm{H}$ NMR spectra, and 150,125 and $100 \mathrm{MHz}$ for recording ${ }^{13} \mathrm{C}$ NMR spectra, respectively. Chemical shifts $(\delta)$ are given in ppm with residual solvent signals as references.

\section{Photophysical characterization. Both UV-Vis absorption and fluorescence} spectroscopic experiments were performed at $298 \mathrm{~K}$ in $\mathrm{MeCN} / \mathrm{CHCl}_{3}$ (4:1). UV Vis Absorption spectra were recorded on a UV-3600 Shimadzu spectrophotometer in three types of rectangular quartz cells with the light paths of $10 \mathrm{~mm}, 4 \mathrm{~mm}$, and $2 \mathrm{~mm}$, respectively. Fluorescence spectra were measured in two types of rectangular 
quartz cells, with the light paths of $10 \mathrm{~mm}$ and $2 \mathrm{~mm}$, respectively, on JASCO FP-2 750 spectrometer or HORIBA FluoroMax-4 spectrometer, which were equipped with an integrating sphere for absolute fluorescence quantum yields determination.

\section{High-resolution and gradient tandem mass spectrometry. High-resolution} mass spectra (HRMS) for the precursors were recorded on an Agilent 6210 Timeof-Flight (TOF) LC-MS with an ESI source. HRMS and gradient tandem mass spectra for cage and host-guest complexes were recorded on a Waters Synapt G2-Si mass spectrometer equipped with ion-mobility under the following conditions: ESI Capillary voltage, $1.0 \mathrm{kV}$; sample cone voltage, $0 \mathrm{~V}$; source offset, $1.0 \mathrm{~V}$; source temperature, $90^{\circ} \mathrm{C}$; desolvation temperature, $170^{\circ} \mathrm{C}$; cone gas flow, $10 \mathrm{~L} \mathrm{~h}^{-1}$; desolvation gas flow, $200 \mathrm{~L} \mathrm{~h}^{-1}\left(\mathrm{~N}_{2}\right)$.

UV-Vis titration. A $1 \mathrm{mM}$ solution of $\boldsymbol{c}$ - $\mathrm{HBC}$ guest molecules in $\mathrm{CHCl}_{3}$ as the titrating solution was added dropwise to a micromolar solution of TPACage $6 \mathrm{PF}_{6}$ in $\mathrm{MeCN} / \mathrm{CHCl}_{3}$ (4:1). Spectra were recorded from 700 to $400 \mathrm{~nm}$ in $10 \times 10 \times 45 \mathrm{~mm}$ rectangular quartz cells. Binding constants were obtained by fitting a 1:1 isotherm according to the programs available at http://app.supramolecular.org/bindfit/.

ITC titration. All microcalorimetric titrations were performed using a thermostated TA Nano Isothermal Titration Calorimeter at atmospheric pressure and $298 \mathrm{~K}$. The samples were dissolved in a solution of $\mathrm{MeCN} / \mathrm{CHCl}_{3}(4: 1)$ and allowed to equilibrate overnight before use. A solution of TPACage $6 \mathrm{PF}_{6}$ $\left(3 \times 10^{-3} \mathrm{M}\right)$ in a syringe was injected with stirring at $75 \mathrm{rpm}$ into a solution of $\boldsymbol{c}$ HBC $\left(3 \times 10^{-4} \mathrm{M}\right)$ guests in the sample cell with an active volume of $185 \mu \mathrm{L}$. Hindered by (i) the relatively low solubility of $\boldsymbol{c}$ - $\mathrm{HBC}$ guests in $\mathrm{MeCN} / \mathrm{CHCl}_{3}(4: 1)$ and (ii) the small enthalpy changes upon forming the complexes, we found it is difficult to obtain accurate binding constants using a continuous calorimetric titration protocol after multiple attempts. We explored the independent singleinjection experiments to estimate the binding enthalpies for the formation of hostguest complexes. The net reaction heat was obtained by subtracting the dilution heat from the apparent reaction heat.

Crystallizations and X-ray analyses for all complexes. For TPACage• $6 \mathrm{Cl}$ : Dark red single crystals were obtained by slow vapor diffusion of $i \mathrm{Pr}_{2} \mathrm{O}$ into a $1.0 \mathrm{mM}$ solution of TPACage.6Cl in $\mathrm{MeOH}$ over the course of four days. For $3 \mathrm{H}-\mathrm{HBC}$ : Yellow single crystals were obtained by slow evaporation of the $\mathrm{PhMe} / \mathrm{CHCl}_{3}(4: 1)$ solution of $3 \mathrm{H}-\mathrm{HBC}$ over the course of five days. For CORСTPACage $6 \mathrm{Cl}$ complex: Dark red single crystals were obtained by slow vapor diffusion of $\operatorname{ir}_{2} \mathrm{O}$ into a $\mathrm{MeOH} / \mathrm{CHCl}_{3}$ (4:1) solution of TPACage $6 \mathrm{Cl}$ containing excess amounts of $\mathrm{COR}$ over the course of three days after numerous attempts. For $c$ -

HBCCTPACage $6 \mathrm{AsF}_{6}$ complexes: Dark red single crystals were obtained by slow vapor diffusion of $i \mathrm{Pr}_{2} \mathrm{O}$ into a $\mathrm{MeCN} / \mathrm{CHCl}_{3}$ (4:1) solution of equimolar amounts of TPACage $6 \mathrm{AsF}_{6}$ and $\boldsymbol{c}$ - $\mathrm{HBC}$ over the course of three days after numerous attempts. The suitable crystals, which appeared in the tubes, were mounted on a MITIGEN holder in Paratone oil on a Bruker Kappa APEX2 CCD or a Rigaku XtaLAB Synergy diffractometer using CuKa radiation $(\lambda=1.5407 \AA)$. Data were collected using the Bruker APEX-II or Rigaku CrysAlis Pro program. The structures were solved with the ShelXT program using intrinsic phasing and refined with the ShelXL refinement package using least-squares minimization in OLEX2 software.

Irradiation experiments. Two rectangular quartz cells, containing $c$ - HBC $([\boldsymbol{c}-$ HBC $]=0.5 \mathrm{mM})$, and $\boldsymbol{c}$-HBC with 2 equiv. of TPACage ${ }^{6+}([\boldsymbol{c}$-HBC $]=0.5 \mathrm{mM}$, $\left[\right.$ TPACage $\left.^{6+}\right]=1 \mathrm{mM}$ ), respectively, were exposed simultaneously to UV light $(370 \mathrm{~nm})$ in $\mathrm{MeCN} / \mathrm{CHCl}_{3}$ (4:1) solution. The UV-Vis absorption spectra were recorded by diluting the irradiated solution to $10 \mu \mathrm{M}$ in a $10 \times 2 \times 45 \mathrm{~mm}$ quartz cell every $12 \mathrm{~min}$. The emission spectra were recorded by diluting the irradiated solution to $0.4 \mu \mathrm{M}$ in a $10 \times 10 \times 45 \mathrm{~mm}$ quartz cell every $12 \mathrm{~min}$. All the UV-light irradiation experiments were carried out using a Kessil PR160-370 nm LED light source at the power density of $5.7 \mathrm{~mW} / \mathrm{cm}^{2}$, and a Dewar bottle served as concentrating equipment.

Transient absorption measurements. For the ultrafast transient absorption measurements, pump and probe pulses were generated from the 800-nm output of a commercial Ti: sapphire laser $(800 \mathrm{~nm}, 100 \mathrm{fs}$ pulse duration, Coherent Libra, $4 \mathrm{~W}$ ). A portion of the $800-\mathrm{nm}$ output was directed into a commercial optical parametric amplifier (OPA, Coherent TOPAS C) to generate a near-IR signal at either $1400 \mathrm{~nm}$ or $1333 \mathrm{~nm}$. Pump pulses at $350 \mathrm{~nm}$ were generated from the fourth-harmonic generation of the OPA signal at $1400 \mathrm{~nm}$. Pump pulses at $500 \mathrm{~nm}$ were generated through the sum-frequency generation of the OPA signal at $1333 \mathrm{~nm}$ with residual $800 \mathrm{~nm}$ fundamental. White-light continuum probe pulses were generated by focusing a portion of the $800-\mathrm{nm}$ laser output into a 3 -mm thick sapphire plate. For the experiments, the energy of the actinic pump pulse was attenuated to $\sim 0.2 \mu \mathrm{J} /$ pulse. The polarization of the pump pulse was set to a magic angle relative to that of the probe to remove rotational contributions from the signal. The delay time between the pump and probe pulse was stepped from $-1 \mathrm{ps}$ to $1.3 \mathrm{~ns}$ in varying step sizes using a computer-controlled delay stage (Newport
ILS250cc, XPS Q8). The probe pulse was spectrally resolved with a spectrometer (Andor Shamrock 500i) and the spectra were collected by a CCD camera (Andor Newton EMCCD: DU970P-FI)

\section{Data availability}

All the data supporting the conclusions are included in this article and its Supplementary files, or are available from the authors upon reasonable request. The X-ray crystallographic coordinates (Supplementary Data 1) for TPACage.6Cl, 3H-HBC, COR $\subset$ TPACage. $6 \mathrm{Cl}$, $3 \mathrm{H}-\mathrm{HBC} \subset \mathrm{TPACage} \cdot 6 \mathrm{AsF}_{6}$, and $3 \mathrm{Me}-\mathrm{HBC} \subset \mathrm{TPACage} \cdot 6 \mathrm{AsF}_{6}$, reported in this study, have all been deposited at the Cambridge Crystallographic Data Centre (CCDC). The deposition numbers are CCDC 2045289, 2045282, 2045290, 2044797, and 2045291, respectively. These data can be obtained free of charge from The Cambridge Crystallographic Data Centre via www.ccdc.cam.ac.uk/data_request/cif. The Cartesian coordinates (Supplementary Data 1) for optimized structures are included in an individual Supplementary PDF file.

Received: 24 January 2021; Accepted: 26 July 2021; Published online: 31 August 2021

\section{References}

1. Wu, J., Pisula, W. \& Müllen, K. Graphenes as potential material for electronics. Chem. Rev. 107, 718-747 (2007).

2. Ozaki, K., Kawasumi, K., Shibata, M., Ito, H. \& Itami, K. One-shot k-regionselective annulative $\pi$-extension for nanographene synthesis and functionalization. Nat. Commun. 6, 6251 (2015).

3. Koga, Y., Kaneda, T., Saito, Y., Murakami, K. \& Itami, K. Synthesis of partially and fully fused polyaromatics by annulative chlorophenylene dimerization. Science 359, 435-439 (2018)

4. Castro-Fernández, S. et al. Two-photon absorption enhancement by the inclusion of a tropone ring in distorted nanographene ribbons. Angew. Chem., Int. Ed. 59, 7139-7145 (2020).

5. Narita, A., Wang, X. Y., Feng, X. \& Müllen, K. New advances in nanographene chemistry. Chem. Soc. Rev. 44, 6616-6643 (2015).

6. Hill, J. P. et al. Self-assembled hexa-peri-hexabenzocoronene graphitic nanotube. Science 304, 1481-1483 (2004).

7. Kang, J. et al. A rational strategy for the realization of chain-growth supramolecular polymerization. Science 347, 646-651 (2015).

8. Li, G. et al. Dearomatization approach toward a superbenzoquinone-based diradicaloid, tetraradicaloid, and hexaradicaloid. Angew. Chem., Int. Ed. 58, 14319-14326 (2019).

9. Yamamoto, Y. et al. Photoconductive coaxial nanotubes of molecularly connected electron donor and acceptor layers. Science 314, 1761-1764 (2006).

10. Kang, S. J. et al. Using self-organization to control morphology in molecular photovoltaics. J. Am. Chem. Soc. 135, 2207-2212 (2013).

11. Huang, Q. et al. Photoconductive curved-nanographene/fullerene supramolecular heterojunctions. Angew. Chem., Int. Ed. 58, 6244-6249 (2019).

12. Wu, Y. T. \& Siegel, J. S. Aromatic molecular-bowl hydrocarbons: Synthetic derivatives, their structures, and physical properties. Chem. Rev. 106, 4843-4867 (2006).

13. Stabel, A., Herwig, P., Müllen, K. \& Rabe, J. P. Diodelike current-voltage curves for a single molecule-tunneling spectroscopy with submolecular resolution of an alkylated, peri-condensed hexabenzocoronene. Angew. Chem., Int. Ed. Engl. 34, 1609-1611 (1995).

14. Müllen, K. \& Rabe, J. P. Nanographenes as active components of singlemolecule electronics and how a scanning tunneling microscope puts them to work. Acc. Chem. Res. 41, 511-520 (2008).

15. Jiménez, V. G., David, A. H. G., Cuerva, J. M., Blanco, V. \& Campaña, A. G. A macrocycle based on a heptagon-containing hexa-peri-hexabenzocoronene. Angew. Chem., Int. Ed. 59, 15124-15128 (2020).

16. Clar, E. \& Stephen, J. F. The synthesis of $1: 2,3: 4,5: 6,7: 8,9: 10,11: 12-$ hexabenzocoronene. Tetrahedron 21, 467-470 (1965).

17. Xiao, S. et al. Controlled doping in thin-film transistors of large contorted aromatic compounds. Angew. Chem., Int. Ed. 52, 4558-4562 (2013).

18. Pisula, W. et al. A zone-casting technique for device fabrication of field-effect transistors based on discotic hexa-peri-hexabenzocoronene. Adv. Mater. 17, 684-689 (2005).

19. Zoppi, L., Martin-Samos, L. \& Baldridge, K. K. Effect of molecular packing on corannulene-based materials electroluminescence. J. Am. Chem. Soc. 133, 14002-14009 (2011)

20. Wang, Y. et al. Two-photon excited deep-red and near-infrared emissive organic co-crystals. Nat. Commun. 11, 4633 (2020). 
21. Pedersen, C. J. The discovery of crown ethers (Noble lecture). Angew. Chem., Int. Ed. Engl. 27, 1021-1027 (1988).

22. Lehn, J.-M. Supramolecular chemistry-scope and perspectives molecules, supermolecules, and molecular devices (Nobel lecture). Angew. Chem., Int. Ed. Engl. 27, 89-112 (1988).

23. Cram, D. J. The design of molecular hosts, guests, and their complexes (Nobel lecture). Angew. Chem., Int. Ed. Engl. 27, 1009-1020 (1988).

24. Kim, K. et al. Functionalized cucurbiturils and their applications. Chem. Soc. Rev. 36, 267-279 (2007).

25. Harada, A., Takashima, Y. \& Nakahata, M. Supramolecular polymeric materials via cyclodextrin-guest interactions. Acc. Chem. Res. 47, 2128-2140 (2014).

26. Liu, C., Ni, Y., Lu, X., Li, G. \& Wu, J. Global aromaticity in macrocyclic polyradicaloids: Hückel's rule or Baird's rule? Acc. Chem. Res. 52, 2309-2321 (2019).

27. Ronson, T. K., Meng, W. \& Nitschke, J. R. Design principles for the optimization of guest binding in aromatic-paneled $\mathrm{Fe}(\mathrm{II})_{4} \mathrm{~L}_{6}$ cages. J. $A m$. Chem. Soc. 139, 9698-9707 (2017).

28. Yazaki, K. et al. Polyaromatic molecular peanuts. Nat. Commun. 8, 15914 (2017).

29. Wu, G. et al. Controllable self-assembly of macrocycles in water for isolating aromatic hydrocarbon isomers. J. Am. Chem. Soc. 140, 5955-5961 (2018).

30. Lozano, D., Alvarez-Yebra, R., Lopez-Coll, R. \& Lledo, A. A flexible selffolding receptor for coronene. Chem. Sci. 10, 10351-10355 (2019).

31. Samanta, S. K. \& Schmittel, M. Guest encapsulation and coronene- $\mathrm{C}_{60}$ exchange in supramolecular zinc porphyrin tweezers, grids and prisms. Org. Biomol. Chem. 11, 3108-3115 (2013).

32. Duan, H. et al. Host-guest recognition and fluorescence of a tetraphenylethene-based octacationic cage. Angew. Chem., Int. Ed. 59, 10101-10110 (2020).

33. Ibanez, S. \& Peris, E. A rigid trigonal-prismatic hexagold metallocage that behaves as a coronene trap. Angew. Chem., Int. Ed. 58, 6693-6697 (2019).

34. Zhang, D., Ronson, T. K., Lavendomme, R. \& Nitschke, J. R. Selective separation of polyaromatic hydrocarbons by phase transfer of coordination cages. J. Am. Chem. Soc. 141, 18949-18953 (2019).

35. Okazaki, T. et al. Coaxially stacked coronene columns inside single-walled carbon nanotubes. Angew. Chem., Int. Ed. 50, 4853-4857 (2011).

36. Juríček, $M$. et al. Induced-fit catalysis of corannulene bowl-to-bowl inversion. Nat. Chem. 6, 222-228 (2014).

37. Schmidt, B. M., Osuga, T., Sawada, T., Hoshino, M. \& Fujita, M. Compressed corannulene in a molecular cage. Angew. Chem., Int. Ed. 55, 1561-1564 (2016).

38. Matsuno, T. et al. $\pi$ arrays for single-axis rotations of a bowl in a tube. Nat. Commun. 9, 3779 (2018).

39. Kishida, N. et al. Anisotropic contraction of a polyaromatic capsule and its cavity-induced compression effect. J. Am. Chem. Soc. 142, 9599-9603 (2020).

40. Ibanez, S. \& Peris, E. Dimensional matching versus induced-fit distortions: Binding affinities of planar and curved polyaromatic hydrocarbons with a tetragold metallorectangle. Angew. Chem., Int. Ed. 59, 6860-6865 (2020).

41. Hayashi, H., Aratani, N. \& Yamada, H. Semiconducting self-assembled nanofibers prepared from photostable octafluorinated bisanthene derivatives. Chem. Eur. J. 23, 7000-7008 (2017).

42. Yang, W., Monteiro, J., de Bettencourt-Dias, A., Catalano, V. J. \& Chalifoux, W. A. Synthesis, structure, photophysical properties, and photostability of benzodipyrenes. Chem. Eur. J. 25, 1441-1445 (2019).

43. Maliakal, A., Raghavachari, K., Katz, H., Chandross, E. \& Siegrist, T. Photochemical stability of pentacene and a substituted pentacene in solution and in thin films. Chem. Mater. 16, 4980-4986 (2004).

44. Watanabe, M. et al. The synthesis, crystal structure and charge-transport properties of hexacene. Nat. Chem. 4, 574-578 (2012).

45. Ikeda, A. \& Shinkai, S. Novel cavity design using calix[n]arene skeletons: Toward molecular recognition and metal binding. Chem. Rev. 97, 1713-1734 (1997).

46. Gale, P. A., Anzenbacher, P. Jr \& Sessler, J. L. Calixpyrroles II. Coord. Chem. Rev. 222, 57-102 (2001).

47. Kim, D. S. \& Sessler, J. L. Calix[4]pyrroles: Versatile molecular containers with ion transport, recognition, and molecular switching functions. Chem. Soc. Rev. 44, 532-546 (2015).

48. Lee, S., Chen, C. H. \& Flood, A. H. A pentagonal cyanostar macrocycle with cyanostilbene $\mathrm{CH}$ donors binds anions and forms dialkylphosphate [3] rotaxanes. Nat. Chem. 5, 704-710 (2013).

49. Liu, Y., Sengupta, A., Raghavachari, K. \& Flood, A. H. Anion binding in solution: Beyond the electrostatic regime. Chem 3, 411-427 (2017).

50. Xue, M., Yang, Y., Chi, X., Zhang, Z. \& Huang, F. Pillararenes, a new class of macrocycles for supramolecular chemistry. Acc. Chem. Res. 45, 1294-1308 (2012).

51. Song, N., Kakuta, T., Yamagishi, T.-A., Yang, Y.-W. \& Ogoshi, T. Molecularscale porous materials based on pillar[n]arenes. Chem 4, 2029-2053 (2018).
52. Odell, B. et al. Cyclobis(paraquat-p-phenylene). A tetracationic multipurpose receptor. Angew. Chem., Int. Ed. Engl. 27, 1547-1550 (1988).

53. Ashton, P. R. et al. Isostructural, alternately-charged receptor stacks. The inclusion complexes of hydroquinone and catechol dimethyl ethers with cyclobis(paraquat-p-phenylene). Angew. Chem., Int. Ed. Engl. 27, 1550-1553 (1988).

54. Frasconi, M. et al. Redox control of the binding modes of an organic receptor. J. Am. Chem. Soc. 137, 11057-11068 (2015).

55. Stoddart, J. F. The chemistry of the mechanical bond. Chem. Soc. Rev. $\mathbf{3 8}$ 1802-1820 (2009).

56. Dale, E. J. et al. Excage. J. Am. Chem. Soc. 136, 10669-10682 (2014)

57. Hafezi, N. et al. Modulating the binding of polycyclic aromatic hydrocarbons inside a hexacationic cage by anion- $\pi$ interactions. Angew. Chem., Int. Ed. $\mathbf{5 4}$, 456-461 (2015).

58. Hasell, T. \& Cooper, A. I. Porous organic cages: Soluble, modular and molecular pores. Nat. Rev. Mater. 1, 16053 (2016).

59. Liu, M. et al. Barely porous organic cages for hydrogen isotope separation. Science 366, 613-620 (2019).

60. Yuan, Y. D. et al. Porous organic cages as synthetic water channels. Nat. Commun. 11, 4927 (2020).

61. Dale, E. J. et al. Supramolecular explorations: Exhibiting the extent of extended cationic cyclophanes. Acc. Chem. Res. 49, 262-273 (2016).

62. Zhang, Q. et al. Facile bottom-up synthesis of coronene-based 3-fold symmetrical and highly substituted nanographenes from simple aromatics. $J$. Am. Chem. Soc. 136, 5057-5064 (2014).

63. Peck, E. M. et al. Rapid macrocycle threading by a fluorescent dye-polymer conjugate in water with nanomolar affinity. J. Am. Chem. Soc. 137, 8668-8671 (2015).

64. Barnes, J. C. et al. Semiconducting single crystals comprising segregated arrays of complexes of $\mathrm{C}_{60}$. J. Am. Chem. Soc. 137, 2392-2399 (2015).

65. Koshland, D. E. The key-lock theory and the induced fit theory. Angew. Chem., Int. Ed. Engl. 33, 2375-2378 (1994).

66. $\mathrm{Wu}, \mathrm{H}$. et al. Ring-in-ring(s) complexes exhibiting tunable multicolor photoluminescence. J. Am. Chem. Soc. 142, 16849-16860 (2020).

67. Hua, Y. \& Flood, A. H. Click chemistry generates privileged CH hydrogenbonding triazoles: The latest addition to anion supramolecular chemistry. Chem. Soc. Rev. 39, 1262-1271 (2010).

68. Xia, D. et al. Functional supramolecular polymeric networks: The marriage of covalent polymers and macrocycle-based host-guest interactions. Chem. Rev. 120, 6070-6123 (2020).

69. Raymo, F. M. \& Stoddart, J. F. Interlocked macromolecules. Chem. Rev. 99, 1643-1664 (1999).

70. Blanco, M. et al. Positive and negative regulation of carbon nanotube catalysts through encapsulation within macrocycles. Nat. Commun. 9, 2671 (2018).

\section{Acknowledgements}

The authors thank Northwestern University (NU) for its support of this research. This research made use of the IMSERC X-ray crystallography facility at Northwestern University, which has received support from the Soft and Hybrid Nanotechnology Experimental (SHyNE) Resource (NSF ECCS-2025633), and Northwestern University. The authors would like to thank Professor Bradley D. Smith for technical support relating to the stopped-flow experiments. H.W., J.Z., L.O.J., W.L., J.M.A., G.C.S., and J.F.S. are grateful for support from the Center for Sustainable Separations of Metals (CSSM), a National Science Foundation (NSF) Center for Chemical Innovation (CCI), grant number CHE-1925708. O.K.F. acknowledges the support from the Defense Threat Reduction Agency under award number HDTRA1-19-1-0010. Theoretical investigations were supported by the Department of Energy, as part of the Center for Molecular Quantum Transduction (CMQT) under grant DE-SC0021314. Theoretical investigations were also supported in part by the computational resources and staff contributions provided for by the Quest High-Performance Computing Facility at NU, which is jointly supported by the Office of the Provost, the Office for Research, and Northwestern University Information Technology.

\section{Author contributions}

H.W. and Y.W. conceived the research, carried out the major experiments and analyses B.S. did the MS analysis. H.J.W. and Y.L. carried out the part of photophysical measurements. J.Z. and J.M.A. performed the transient absorption measurements. Y.S. and J.W. prepared one of the guests. L.O.J., W.L., and G.C.S. conducted theoretical calculations. C.L.S., X.Z., L.Z., and O.K.F. carried out the X-ray crystallographic analyses. H.W and Y.W. wrote the manuscript. K.C. and X.C. were involved in the discussions and contributed to the manuscript preparation. J.F.S. and Y.L. directed and supervised the research. All authors discussed the experimental results and contributed to the preparation of the manuscript. 


\section{Competing interests}

The authors declare no competing interests.

\section{Additional information}

Supplementary information The online version contains supplementary material available at https://doi.org/10.1038/s41467-021-25255-6.

Correspondence and requests for materials should be addressed to Y.L. or J.F.S.

Peer review information Nature Communications thanks Susana Ibáñez and the other, anonymous, reviewer(s) for their contribution to the peer review of this work.

Reprints and permission information is available at http://www.nature.com/reprints

Publisher's note Springer Nature remains neutral with regard to jurisdictional claims in published maps and institutional affiliations. (c) (i) Open Access This article is licensed under a Creative Commons Attribution 4.0 International License, which permits use, sharing, adaptation, distribution and reproduction in any medium or format, as long as you give appropriate credit to the original author(s) and the source, provide a link to the Creative Commons license, and indicate if changes were made. The images or other third party material in this article are included in the article's Creative Commons license, unless indicated otherwise in a credit line to the material. If material is not included in the article's Creative Commons license and your intended use is not permitted by statutory regulation or exceeds the permitted use, you will need to obtain permission directly from the copyright holder. To view a copy of this license, visit http://creativecommons.org/ licenses/by/4.0/.

(C) The Author(s) 2021 